Running head - Valuing flexibility with CCS

Article type - Original research paper (special issue on CCS)

Full title - Valuing power plant flexibility with CCS: the case of post-combustion capture retrofits Authors - Hannah Chalmers ${ }^{1,2}$, Jon Gibbins ${ }^{2}$ and Matt Leach ${ }^{1}$

Affiliations

1 Centre for Environmental Strategy, University of Surrey, Guilford, GU2 7XH, UK

2 School of Engineering, The King's Buildings, University of Edinburgh, Edinburgh, EH9 3JL

Details for corresponding author

Hannah Chalmers

Institute for Energy Systems

School of Engineering

Faraday Building

The King's Buildings

University of Edinburgh

Edinburgh

EH9 3JL

E-mail: hannah.chalmers@ed.ac.uk

Phone: +44(0)7888 801020

Fax: +44(0)131 6506554 


\title{
Valuing power plant flexibility with CCS: the case of post-combustion capture retrofits
} Hannah Chalmers, Jon Gibbins and Matt Leach

\begin{abstract}
An important development in recent years has been increased interest in retrofitting $\mathrm{CO}_{2}$ capture at existing power plants. In parallel, it has also been suggested that flexible operation of power plants with $\mathrm{CO}_{2}$ capture could be important in at least some jurisdictions. It is likely that retrofitted power plants could have significant 'built-in' flexibility, but this potential is often not considered in studies of the economic performance of power plants with $\mathrm{CO}_{2}$ capture. This paper makes a contribution to filling this gap by developing methods for first order screening analysis of flexible operation of power plants with $\mathrm{CO}_{2}$ capture and applying them to the case study example of an appropriately integrated retrofit of post-combustion capture at a coal-fired power plant. The quantitative analysis suggests that rich solvent storage could be an attractive option on a short-run basis for some fuel, $\mathrm{CO}_{2}$ and electricity price combinations. Results from first order analysis can then be used to determine which operating modes should (and shouldn't) be included in further, more detailed design studies.
\end{abstract}

Keywords: carbon capture and storage; flexibility; post-combustion capture; power plant operation; retrofit

\section{Introduction}

Carbon capture and storage (CCS) technologies could be used to significantly reduce carbon dioxide $\left(\mathrm{CO}_{2}\right)$ emissions from large point sources such as power plants and cement manufacture. A typical CCS project will include separation of $\mathrm{CO}_{2}$ from other product or waste streams (capture), followed by transport to long-term storage in a geological formation deep below the surface of the earth. A number of comprehensive introductions to CCS are available in the literature, including an Intergovernmental Panel on Climate Change special report (IPCC, 2005). A broad range of options are being developed for CCS applications and are at different levels of commercial readiness. Although significant fundamental research at laboratory and pilot scales is ongoing, a number of options can already be ordered from vendors at commercial scale (UKCCSC, 2011).

At the time of writing, a number of commercial scale CCS demonstration projects at power plants are under development, including several projects that would retrofit $\mathrm{CO}_{2}$ capture at an existing plant (e.g. SaskPower, 2011; ScottishPower, 2010). It is, therefore, becoming increasingly important to develop a more sophisticated understanding of a broad range of issues that could have a significant impact on the attractiveness of CCS projects to developers and investors.

The majority of initial studies on CCS plant design and economics have assumed that power plants installed with CCS will be 'baseload' plants, which are very likely to be operated whenever they are available. One issue that has been attracting increasing attention in recent years, however, is characterising and valuing operating flexibility of $\mathrm{CO}_{2}$ capture at power plants. In many jurisdictions, targets for significant deployment of renewable electricity generating options are expected to lead to major impacts on the operating patterns of fossil-fired power plants. The operating costs for generating electricity from many renewable sources (e.g. wind, wave, solar) are typically much lower than for fossil-fired power plants since no fuel purchase is required. This, therefore, means that renewable sources can be expected to be used in preference to fossil-fired power plants when they are available. Since many renewable resources are intermittent, it is generally accepted that some fossil-fired power plants are likely to continue to play a significant role in ensuring that electricity supply balances demand. These plants will, however, be expected to be more responsive plants that will not always be used when they are available. 
There is, however, very limited quantitative analysis of likely changes in the way fossil-fired power plants are operated flexibly when they have $\mathrm{CO}_{2}$ capture installed (e.g. see IEA GHG, 2008; IEA GHG, 2009; Chalmers, 2010a). The approaches developed in this paper use the illustrative case of an existing coal-fired power plant that has been retrofitted with an appropriately integrated postcombustion capture process to explore if and how operating flexibility might be important and hence be exploited for commercial advantage. This example is chosen since there has been a relatively recent resurgence of interest in retrofitting $\mathrm{CO}_{2}$ capture to power plants, with an associated reassessment of which factors are sufficiently important to be included in quantitative analysis, as discussed in Section 2.

As outlined in Section 4, it appears likely that retrofitted plants could have significant built-in flexibility. There has, however, been little or no acknowledgement of the implications of this within the public domain literature as discussed in Section 3. It is, therefore, timely to review the potential commercial importance of operating flexibility at these plants so that ongoing and future analysis can be adapted to take into account, where appropriate, modes of flexibility that could be significant.

Much of the work presented in this paper explores a case study example of solvent storage at plants using post-combustion capture. Section 4 updates and extends the first order technical characterisation of this option presented by Chalmers and Gibbins (2007). Section 5 then reports key results from techno-economic analysis, with a particular focus on understanding under what conditions solvent storage might be important. Some implications of this case study analysis and also potential priorities for future work are then discussed in Section 6.

Although this paper focuses on illustrative case studies, it is intended that these examples can make a broader contribution by developing methodologies that can be used by individuals or organisations undertaking first order screening analysis of CCS options. For example, the concept of a 'decision diagram' is explored in Section 5.2.1. This visual summary allows practitioners to easily identify which operating modes are (and, arguably more importantly, are not) likely to be used by CCS power plants under electricity and $\mathrm{CO}_{2}$ price scenarios that are relevant for their situation. Additionally, we propose the use of two new metrics (adjusted short run marginal cost and short run net cash flow) which modify familiar concepts in electricity economics to allow more rapid comparison and appraisal of the cost and revenue changes associated with flexible operation of CCS power plants.

Finally, it is important to note that this paper does not aim to draw conclusions on whether investment to improve flexibility at power plants with CCS is worthwhile. This would require system-specific information on factors such as anticipated electricity selling price and $\mathrm{CO}_{2}$ price. Additional work to determine capital costs for any plant modifications, which is beyond the scope of this paper, would also be needed. The methodologies developed here can be used by operators after an investment decision has been made since they will seek to maximise the value of an asset that investors have already supported. They should also be useful for other analysts and decisionmakers who can use the results obtained by applying the approaches developed in this paper to inform decisions about priorities for further work such as detailed engineering studies for capital cost estimation or electricity system simulations.

\section{Developments in understanding of $\mathrm{CO}_{2}$ capture retrofits since IPCC (2005)}

Although much of the literature on CCS addresses new build power plants that have $\mathrm{CO}_{2}$ capture installed at the outset, there is also some literature on retrofitting $\mathrm{CO}_{2}$ capture to existing plants. In 
recent years it has been recognised that the value of existing plants can be considerable. For example, a 2009 symposium on retrofitting coal-fired power plants for $\mathrm{CO}_{2}$ emissions reductions (MIT Energy Initiative, 2009) noted that:

"owners and operators of coal-fired power plants possess valuable assets above and beyond affordable power. For example, existing coal plants are strategically located on the electric grid transmission system. They have substantial plant infrastructure, hold difficult-to-obtain site and environmental permits, and have access to existing water and coal transportation infrastructures. The value of these assets should not be underestimated when making policy, technology, and investment decisions on mitigating carbon emissions."

The IPCC (2005) special report on CCS summarised the main conclusions from early literature on retrofitting CCS to existing power plants. It noted that retrofitting existing power plants with $\mathrm{CO}_{2}$ capture had not been "extensively studied" but that the limited literature available suggested that retrofitting post-combustion capture would lead to higher costs than those expected for new-build sites. A number of disadvantages associated with retrofit projects were identified in IPCC (2005), but the potential need to retrofit existing plants so that any rapid introduction of $\mathrm{CO}_{2}$ capture would not mean that existing plants "have to be retired prematurely and replaced by new plants with capture” was also acknowledged.

Although the IPCC (2005) special report noted that the literature had tended to suggest that $\mathrm{CO}_{2}$ capture retrofits were likely to be combined with application of supercritical boiler/turbine technology, a few studies did continue to explore the potential to retrofit $\mathrm{CO}_{2}$ capture to sub-critical plants without such an extensive boiler/turbine upgrade (e.g. Ploumen, 2006; Ramezan et al, 2007). More recently, there has been a resurgence of interest in retrofitting $\mathrm{CO}_{2}$ capture to existing plants without a boiler/turbine upgrade (e.g. Doosan Babcock, 2009; ScottishPower, 2010). A number of factors may have driven this change including variations in costs for new-build power plant projects (e.g. see Holt et al, 2009; Davison and Thambitmuthu, 2009).

Finally, the discourse and related literature addressing technical and economic issues related to retrofitting $\mathrm{CO}_{2}$ capture to existing plants appears to be evolving to take account of the value of avoiding or, at least delaying, capital expenditure associated with building a new power plant if an existing plant can remain in service for longer due to a $\mathrm{CO}_{2}$ capture retrofit. For example, a recent study for the IEA Greenhouse Gas R\&D Programme (IEAGHG, 2011) included a generic assessment of options available for retrofitting CCS to power plants. It concluded that:

"For a range of conditions that might be encountered in practice it appears that the costs of electricity from power plants retrofitted with CCS may be lower than from new build power plants with CCS... [R]etrofitting CCS to existing power plants is worth examining objectively as an alternative to closing down existing plants and replacing them with new build plants, when a reduction in $\mathrm{CO}_{2}$ emissions from an existing fossil power plant fleet is required."

\section{Operating flexibility at retrofitted power plants}

The focus of the remainder of this paper is to improve understanding of the potential value of intrinsic flexibility of power plants retrofitted with $\mathrm{CO}_{2}$ capture, using the case study example of post-combustion capture retrofitted to a coal-fired power plant. As already noted there has been very limited analysis of the potential for flexible operation of power plants with $\mathrm{CO}_{2}$ capture to have a significant influence on the likely technical and/or economic performance of retrofitting $\mathrm{CO}_{2}$ capture to existing power plants. A few contributions have, however, been identified and are discussed in this Section. 


\subsection{Technical overview}

Post-combustion capture involves relatively few changes to conventional power plants since it is added as a last stage of emissions cleaning, as illustrated in Figure 1. $\mathrm{CO}_{2}$ is separated from other flue gases in a two-stage process. First, the $\mathrm{CO}_{2}$ is removed from the flue gas in the absorber using a slightly alkaline solvent (often based on amines, typically monoethanolamine (MEA), or on ammonia). This is a reversible reaction and in the second stage the solvent is heated to release the $\mathrm{CO}_{2}$. The 'regenerated' solvent is then recycled for reuse and the produced $\mathrm{CO}_{2}$ is dried and compressed before it is transported to safe storage (or use). The majority of the power plant efficiency penalty associated with post-combustion capture occurs as a consequence of the regeneration of the solvent and compression of the captured $\mathrm{CO}_{2}$.

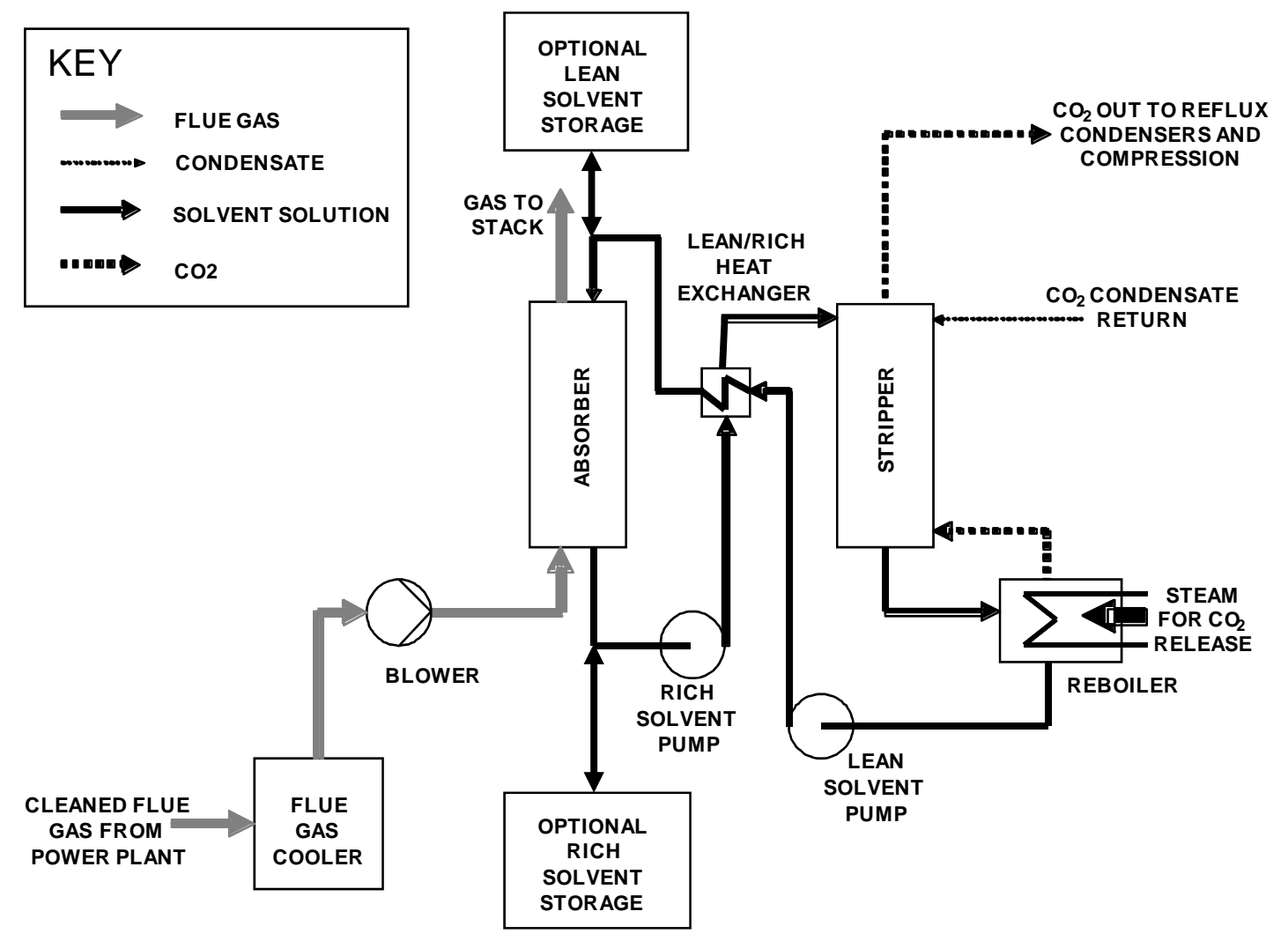

Figure 1 Post-combustion capture plant with optional solvent storage tanks (Chalmers et al, 2009)

It is possible that changes in $\mathrm{CO}_{2}$ capture rate and plant configuration could provide extra operating modes that are valuable to plant operators and should, therefore, be considered by investors and regulators. One operating option is stopping (or reducing) $\mathrm{CO}_{2}$ capture for a short period of time (e.g. when electricity prices are at peak values) in order to increase plant efficiency and electrical output, which can be achieved by bypassing the capture unit. The ability to operate with reduced capture levels, or without any capture at all, may be specified as part of the basic design of, at least some, plants if it is allowed under future permitting regimes. Although bypass of $\mathrm{CO}_{2}$ capture increases $\mathrm{CO}_{2}$ emissions from a given plant in the short term, it would not lead to a global increase in $\mathrm{CO}_{2}$ emissions if the plant is operating in a system where total emissions are limited over a period of time (e.g. the European Emissions Trading Scheme).

An additional option, which is illustrated in Figure 1, is to add solvent storage tanks between the absorber and stripper so that the majority of the electricity output penalty for $\mathrm{CO}_{2}$ capture can be decoupled from the time when $\mathrm{CO}_{2}$ is produced without a significant reduction in $\mathrm{CO}_{2}$ capture rate. 
If solvent storage is available then 'rich' solvent that contains $\mathrm{CO}_{2}$ removed from power plant flue gases can be held up in an interim storage tank, rather than being sent to the stripper/reboiler for immediate regeneration. This stored rich solvent can then be regenerated by adding it to rich solvent generated by ongoing operations at a later time. Previously-stored lean solvent from another tank is used to allow capture to continue. Some investment in $\mathrm{CO}_{2}$ handling capacity downstream of the absorber may be needed to allow a period of 'additional regeneration' to occur depending on variations in power plant fuel input (see further discussion below).

Investors will need to determine whether the expenditure required to facilitate solvent storage is likely to be worthwhile and, if so, what level of investment should be made. Detailed engineering design for this option does not appear to be available in the public domain at the time of writing. Gibbins and Crane (2004), Haines and Davison (2009) and Chalmers et al (2009) have, however, all reported initial cost estimates for solvent storage tanks and related additional solvent inventory. For example, Chalmers et al (2009) suggested that around $10,000 \mathrm{~m}^{3} / \mathrm{hr}$ of solvent storage capacity would be required for $90 \% \mathrm{CO}_{2}$ capture using an MEA-based solvent at an illustrative supercritical coal-fired power plant with a net output of 666MW with capture, allowing a potential rise in output to around 825MW when solvent is stored. Depending on materials choice, this work suggested that total capital requirement for the capture and compression island (as configured for operation without solvent storage) would be likely to increase by around $10-20 \%$ if solvent storage tanks were installed and additional solvent inventory to facilitate 2 to 4 hours of solvent storage was bought. It was, therefore, suggested that:

"Solvent storage system costs are thus likely to be a relatively small addition to the total for a plant, but whether or not these represent a worthwhile investment obviously depends on future operating environments and whether or not potential alternatives such as pumped hydro storage could be used instead."

Gibbins and Crane (2004) and Haines and Davison (2009) also concluded that solvent storage could be a competitive option within the electricity system, but that further work is required to improve understanding of how solvent storage would be implemented at real plants. Additionally, it will be important to undertake further work to establish dynamic performance of solvent storage systems. Initial indications are, however, that response times of order minutes should be possible (Chalmers et al, 2009).

\subsection{Initial economic analysis}

Fuss et al (2008) investigated the importance of stable climate policy signals for the diffusion of CCS in the power sector using a real options model with stochastic electricity and $\mathrm{CO}_{2}$ prices. They considered both managerial flexibility to choose when to retrofit capture (if at all) and operating flexibility to not operate the unit once it is installed. It was found that capture plant bypass was not used and Fuss et al (2008) attributed this to their assumed increasing $\mathrm{CO}_{2}$ prices. Szolgayova et al (2008) used a model with a similar structure to explore investment in coal or biomass plants (both with the potential to have CCS retrofitted) to replace an existing coal plant. In this work, some limited use of capture plant bypass is reported, possibly due to lower $\mathrm{CO}_{2}$ prices being observed in this study. It is likely, however, that the analyses in both studies failed to characterise possibly different trends for behaviour during peaks in electricity price since they focussed only on annual average electricity prices.

A set of studies led by Cohen at the University of Texas at Austin have used a model of the Texas electricity system to explore how power plants retrofitted with $\mathrm{CO}_{2}$ capture might operate within electricity networks on an hour-by-hour basis. Cohen et al (2008) introduced a simplified model of plant dispatch (i.e. which plants are operating at any given time). Further work using this model has explored how fuel price variations might affect capture plant bypass operating decisions (Cohen et 
al, 2009a; Cohen, 2009b). It found that higher natural gas prices, which generally lead to higher electricity prices in this system, tended to increase the likelihood that capture plant bypass would be economically attractive. Reductions in coal price were reported to have limited impacts on operating decisions but would tend to increase profitability, which would be expected at any plant where operating costs have been reduced but revenue has not changed.

More recently, Cohen et al (2011) extended previous work to compare likely post-combustion capture operation in the Texas and Great Britain electricity systems. Again, power plant flexibility to bypass the capture unit was included and the focus was on coal-fired power plant operation with CCS installed (although it should be noted that there has also been increasing interest in $\mathrm{CO}_{2}$ capture on natural gas power plants in the UK). These two systems have similar installed overall amounts of generation capacity, but different capacity mixes, demand patterns and fuel markets. One important difference observed when these systems are compared is that, while Texas coal-fired power plants tend to operate whenever they are available (baseload), many British coal-fired power plants are used less frequently. Coal is typically more expensive in Britain than in Texas, and there is also currently more competition from non-coal fuel sources for power generation in Britain than in Texas. It is, therefore, suggested that as $\mathrm{CO}_{2}$ prices increase it is likely that $\mathrm{CO}_{2}$ capture will be more important to British coal-fired power plants for maintaining a reasonable number of operating hours than similar plants in Texas.

No studies that consider other modes of operating flexibility for power plants with $\mathrm{CO}_{2}$ capture within an electricity system simulation have been identified in the public domain. Gibbins and Crane (2004), Chalmers and Gibbins (2007) and Haines and Davison (2009) have, however, presented relatively simple plant-level screening analysis of the potential value of rich solvent storage in addition to capture plant bypass for power plants with post-combustion capture.

Although this work was not particularly focussing on retrofitted plants, it is useful to given an initial indication of reasonable priorities for further work.

A significant observation here is that the results reported in all of these studies suggest that although capture plant bypass could have an important role in certain circumstances, solvent storage is potentially much more significant in the longer term if limits on $\mathrm{CO}_{2}$ emissions from fossil use become increasingly stringent over time. This is because solvent storage improves power plant flexibility but without a significant decrease in the proportion of $\mathrm{CO}_{2}$ captured by the plant. This paper, therefore, extends previous work reporting first order techno-economic screening of the potential use and value of capture plant bypass (Chalmers et al, 2011) and focuses on case studies where solvent storage is available, in addition to capture plant bypass.

\section{Power plant efficiency for flexible operation with post-combustion capture}

Morgan and Henrion (1990) observed that in many cases only a "handful" of variables are very significant in determining output values in modelling exercises and, hence, can be identified as the key factors in decision-making. This means that a first order screening analysis can be useful to provide a rapid initial assessment of new concepts. Any resources devoted to further work can then be focussed on the factors that are expected to be most important in providing insights that are required to make an informed investment (or other) decision.

It is still necessary, however, to carry out screening analysis in sufficient detail to allow a reasonable technical understanding of the particular operating modes that are being considered by this analysis to be developed. The scope of work in this paper is, therefore, limited to two options, capture plant bypass and solvent storage respectively, for providing large amounts of operating 
flexibility with post-combustion capture, with a particular focus on the role of one of them (solvent storage).

The main parameter used to describe power plant technical performance for a given steady state operating point is the thermal efficiency of electricity generation, which is also expressed as its reciprocal, the heat rate. The characterisation of efficiency included here is grounded in a critical review of literature that is reported in more detail in Chalmers (2010b). Efficiencies are reported as net electrical efficiency for conversion of energy in fuel on a lower heating value (LHV) basis to electrical energy output into the electricity system. Since there is a relatively limited literature on retrofitting $\mathrm{CO}_{2}$ capture to power plants, a broader range of work is included in establishing the technical characteristics for this illustrative analysis. This is consistent with assuming reasonable integration is possible, even in a retrofit application, which appears to be technically feasible (Gibbins and Crane, 2004; Xu et al, 2007; Lucquiaud, 2010; IEA GHG, 2011).

\subsection{Base case operation at full and part load}

Table 1 gives an overview of key parameters for base case operation at full load used in the illustrative quantitative analysis in this paper, drawing on IEA GHG (2004) as a baseline study. Perhaps counterintuitively, as commercial-scale deployment of $\mathrm{CO}_{2}$ capture at power plants has come closer to reality there has been very limited further publication of detailed studies considering whole power plant design with $\mathrm{CO}_{2}$ capture that might update benchmark studies such as IEA GHG (2004). Instead, it seems that vendors have begun to work on more detailed, but commercially sensitive studies, for clients exploring $\mathrm{CO}_{2}$ capture deployment options at particular sites (Davison and Thambimuthu, 2009) and perhaps also do not wish to prejudice their ability to make future commercial tenders at project-specific prices.

Table 1 Technical parameters used for power plant performance

\begin{tabular}{|l|c|}
\hline Parameter & Base case \\
\hline Supercritical power plant net electrical efficiency without capture at full load (\%LHV) & $44 \%$ \\
\hline Maximum \% of $\mathrm{CO}_{2}$ captured (\% of $\mathrm{CO}_{2}$ produced) & $90 \%$ \\
\hline $\mathrm{CO}_{2}$ capture efficiency penalty at full load compared to a new-build plant without capture (\% points) & $9 \%$ \\
\hline
\end{tabular}

For consistency, assumptions included in the standard assessment criteria used for the IEA GHG (2004) study are, therefore, also generally applied in this work. For example, it is assumed that decommissioning costs at the end of the plant life are insignificant in construction and operating decisions (e.g. they are low in relative terms and are also offset by the scrap value of the plant). Additionally, performance and costs are also intended to be for relatively mature technology, which is consistent with the majority of the public domain literature on $\mathrm{CO}_{2}$ capture at power plants as well as the IEA GHG standard assessment criteria. It should also be noted that this paper does not consider cases where $\mathrm{CO}_{2}$ capture is applied at a combined heat and power (CHP) facility and that only direct $\mathrm{CO}_{2}$ emissions from fuel combustion at the power plant are considered (i.e. any fuel supply chain emissions are not considered).

Figure 2 illustrates base case part load operation with constant capture rate. Within this paper it is assumed that part load operation is planned, that it occurs in response to changes in wholesale electricity prices and that it is achieved by reducing fuel input. It should be noted, however, that in some suitably designed plants output may alternatively be reduced by other methods, such as bypassing steam directly to a condenser (i.e. not passing all steam through all turbines), probably due to fault conditions or possibly so that an ancillary service can be provided more quickly than would be possible with a change in fuel input. 


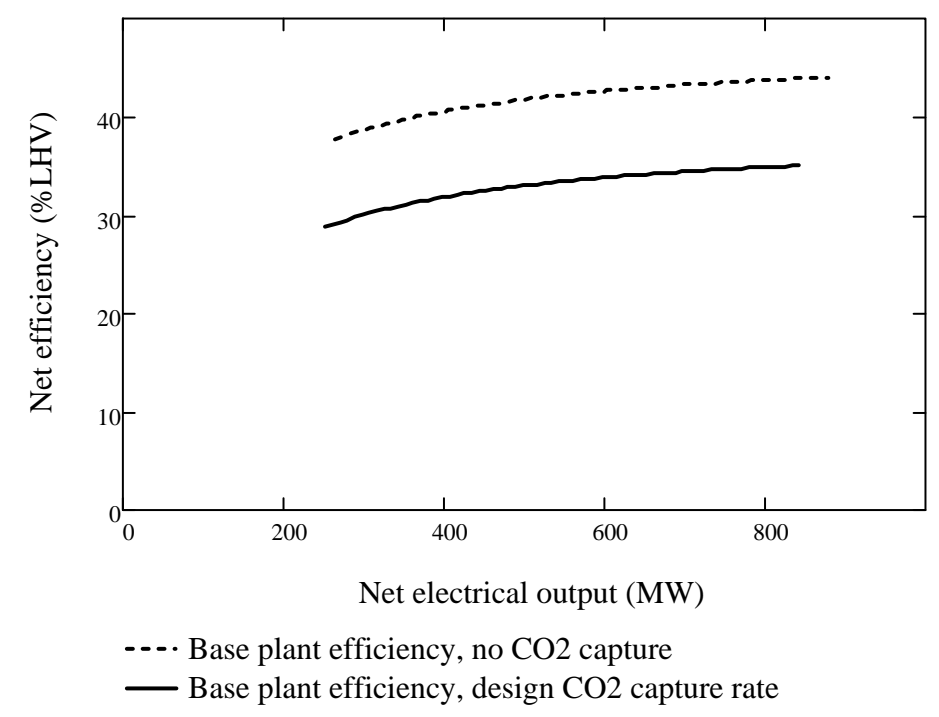

Figure 2 Base case part load operation with constant capture rate

There is very limited public domain data on the part load efficiency of pulverised coal-fired power plants, with or without $\mathrm{CO}_{2}$ capture. This paper, therefore, uses first order approximations of power plant performance that update Chalmers and Gibbins (2007). Base power plant performance without $\mathrm{CO}_{2}$ capture is based on Sakai et al (1999), DTI (1999) and Luby (2003). The literature on dynamic operation of post-combustion capture units indicates that strategies for part load design and operation are not yet clear (e.g. Kvamsdal et al, 2009). As a first-order approximation this work assumes that the overall electricity output penalty for $\mathrm{CO}_{2}$ capture expressed per unit fuel input (and hence as \% point efficiency penalty) will be constant across all loads. This is based on likely trade-offs between a range of impacts that can be expected during part load operation, as outlined in Chalmers and Gibbins (2007). .

\subsection{Performance with capture plant bypass}

A common feature of any capture plant bypass approach where the bypass is planned as an operational response to improve economic performance of the power plant should be a reduction in steam flow to the reboiler, with a consequent increase in steam flow in the low pressure turbines in the power plant steam cycle. If a capture plant is bypassed in response to wholesale electricity prices only (as is the case for the quantitative analysis in this paper) it is reasonable to assume that maximum possible bypass will be used in most, if not all, cases and that bypass would occur during periods of full fuel input, since power output, and hence the revenue increase, would be maximised under these conditions.

An illustrative efficiency penalty of 1 percentage point when the performance of a power plant bypassing $\mathrm{CO}_{2}$ capture is compared to a similar plant where $\mathrm{CO}_{2}$ capture has never been installed is assumed in this work. This follows Lucquiaud et al (2007), where it is assumed that there will be some efficiency penalty during bypass (e.g. due to pressure loss in open throttle valves at the LP turbine inlet).

It should also be noted that an important characteristic of the case study plants considered in this paper is that when a plant is retrofitted with post-combustion $\mathrm{CO}_{2}$ capture, the generator, low pressure (LP) turbine and condenser are assumed to retain their pre-retrofit capacity. The quantitative analysis in this paper is, therefore, for plants that have sufficient capacity in the power cycle to accept increased steam flow when the capture plant is bypassed. This ‘built-in' flexibility is important if capture plant bypass is to be economically attractive. 
This flexibility for a retrofitted plant can be compared to plants designed to operate with capture throughout their operating life. In these cases, investors will need to consider whether they wish to invest in 'over-sizing' of the generator, LP turbine and condenser so that additional electrical energy can be dispatched if $\mathrm{CO}_{2}$ is not captured (either during capture plant bypass or while rich solvent is stored). Indeed, for some configurations, if the capture plant was out of service (e.g. because of a fault) the turbine power output might have to be reduced, since the flow of steam through the turbine high pressure (HP) and intermediate pressure (IP) cylinders would be limited by the capacity of a low pressure (LP) cylinder size, assuming steam extraction at the IP/LP crossover. Tenaska Trailblazer Partners, LLC (2011) concluded that, at least some, real project developers will consider that options made available by 'over-sizing' the generator, LP turbine and condenser are worth the investment, perhaps particularly for initial CCS new-build projects.

\subsection{Performance with rich solvent storage}

Two distinct but linked periods of operation need to be quantified for modelling solvent storage: a period with relatively high electricity selling price where rich solvent is stored and a period of lower electricity selling price where stored rich solvent is regenerated and stored as lean solvent for subsequent use. It is very likely that a full cycle of rich solvent storage followed by later regeneration of stored solvent would be completed within a single day in many cases. Gibbins and Crane (2004) suggested a range of 2 to 8 hours of storage capacity might be worth considering, while Haines and Davison (2009) analysed solvent storage times of 1 to 8 hours and concluded that around 4 hours may provide the best return on investment for the UK example examined in their work.

This paper follows the approach taken in Chalmers and Gibbins (2007) and assumes an illustrative $1 \%$ point efficiency penalty when rich solvent is stored, compared to capture plant bypass, to take account of factors such as absorber tower pressure loss and solvent pumping requirements. During periods of additional regeneration of rich solvent, an increased efficiency penalty will be observed. As in Chalmers and Gibbins (2007), this work assumes that a change in the amount of rich solvent (arising from both storage and current use) being regenerated will lead to a directly proportional change in capture efficiency penalty.

An important consideration in defining solvent storage options for screening analysis is that it is possible that the amounts of rich solvent to be regenerated and $\mathrm{CO}_{2}$ produced could be higher than during 'normal' operations without solvent storage. This would then require that sufficient capacity is available to accommodate this increase in flow in the reboiler/stripper and $\mathrm{CO}_{2}$ compression train. In some cases, oversizing of the $\mathrm{CO}_{2}$ transport and storage system might also be needed. If fuel input is reduced during the period when stored solvent is regenerated this can, however, avoid the need for oversizing of these components when compared to those required for design flow rates without any consideration of potential solvent storage (e.g. see Lucquiaud et al 2007; 2009).

Table 2 shows, respectively, the power plant efficiency while stored solvent is regenerated and the time taken to regenerate stored solvent for four test cases, where regeneration rate (column 1) is defined as the total flow of solvent to the reboiler/stripper as a percentage of the 'normal' flow without regeneration of stored rich solvent at that fuel input (and also the percentage of the 'normal' flow at $100 \%$ fuel input is shown for reference - column 2). These cases cover an operating envelope that is sufficiently large to explore variations in plant performance due to different operating parameters, but that is still sufficiently narrow to avoid extreme operating conditions or limits that could lead to significant deviations from the performance predicted by the first order models being used in this analysis. 
Table 2 Net electrical efficiency during regeneration for test cases in this paper

\begin{tabular}{|c|c|c|c|c|c|}
\hline & \multicolumn{2}{|c|}{$\begin{array}{l}\text { Regeneration rate during } \\
\text { regeneration of stored solvent }\end{array}$} & \multirow{2}{*}{$\begin{array}{l}\text { Fuel } \\
\text { input }\end{array}$} & \multirow{2}{*}{$\begin{array}{c}\text { Net } \\
\text { electrical } \\
\text { efficiency }\end{array}$} & \multirow{2}{*}{$\begin{array}{c}\text { Time to } \\
\text { regenerate } \\
\text { solvent stored in } \\
\text { 1hr operating at } \\
\text { full load }\end{array}$} \\
\hline & $\begin{array}{l}\text { \% of 'normal' } \\
\text { rate at that } \\
\text { fuel input }\end{array}$ & $\begin{array}{l}\% \text { of 'normal' rate } \\
\text { at } 100 \% \text { fuel input }\end{array}$ & & & \\
\hline \multirow{2}{*}{$\begin{array}{l}\text { Full fuel input retained } \\
\text { during regeneration of } \\
\text { stored solvent }\end{array}$} & $125 \%$ & $125 \%$ & $100 \%$ & $32.75 \%$ & $4 \mathrm{hr}$ \\
\hline & $150 \%$ & $150 \%$ & $100 \%$ & $30.50 \%$ & $2 \mathrm{hr}$ \\
\hline \multirow[b]{2}{*}{$\begin{array}{l}\text { Fuel input reduced during } \\
\text { regeneration of stored } \\
\text { solvent so that total } \mathrm{CO}_{2} \\
\text { production is the same as } \\
\text { full capture without rich } \\
\text { solvent storage with full } \\
\text { fuel input }\end{array}$} & $125 \%$ & $100 \%$ & $80 \%$ & $31.95 \%$ & $5 \mathrm{hr}$ \\
\hline & $150 \%$ & $100 \%$ & $67 \%$ & $28.85 \%$ & 3hr \\
\hline
\end{tabular}

\section{Techno-economic analysis of rich solvent storage potential}

The illustrative techno-economic analysis in this paper is limited to exploring whether rich solvent storage (and capture plant bypass) might be attractive operating modes in response to changing energy (electricity) prices from the perspective of a single plant operator. This allows a baseline for likely power plant operator decisions to be established without consideration of specific incentives for flexible operation (e.g. ancillary service payments).

In order to determine expected operating decisions for different fuel/ $\mathrm{CO}_{2}$ price/electricity price scenarios, the concept of an 'adjusted short run marginal cost' is introduced (Section 5.1).

'Decision diagrams' that provide a visual indication of conditions under which rich solvent storage (and capture plant bypass) might be economically attractive are then derived and discussed in Section 5.2. Table 3 provides a summary of the economic factors and other input data not defined in Tables 1 and 2 assumed for the illustrative quantitative examples reported here and in the worked examples in Appendix A.

Table 3 Economic factors and other input data assumed in this paper

\begin{tabular}{|l|c|c|}
\hline Parameter & Base case & Example reference \\
\hline Coal price & $\$ 2.2 / \mathrm{GJ}$ & IEA GHG (2006) update to IEA GHG (2004) \\
\hline Fuel heat input & $1913 \mathrm{MW}$ & IEA GHG (2004) \\
\hline $\begin{array}{l}\text { Fuel specific } \mathrm{CO}_{2} \text { emissions (as } \\
\text { received) }\end{array}$ & $92 \mathrm{kgCO}_{2} / \mathrm{GJ} \mathrm{LHV}$ & IEA GHG (2004) \\
\hline $\mathrm{CO}_{2}$ price & $\$ 0-100 / \mathrm{tCO}_{2}$ & MIT (2007) \\
\hline $\begin{array}{l}\text { Other non-CCS related operating } \\
\text { expenditure }\end{array}$ & $\$ 0.5 / \mathrm{MWh}$ & IEA GHG (2004) \\
\hline $\begin{array}{l}\text { Variable expenditure for } \mathrm{CO}_{2} \\
\text { capture }\end{array}$ & $\$ 3.5 / \mathrm{tCO}{ }_{2}$ captured & IEA GHG (2004) \\
\hline $\begin{array}{l}\text { CO }{ }_{2} \text { transport and storage price } \\
\text { Illustrative low wholesale } \\
\text { electricity price }\end{array}$ & $\$ 10 / \mathrm{tCO} \mathrm{O}_{2}$ captured & See discussion in Chalmers (2010b) \\
\hline $\begin{array}{l}\text { Illustrative peak wholesale } \\
\text { electricity price }\end{array}$ & $\$ 35-55 / \mathrm{MWh}$ & See discussion in Chalmers (2010b) \\
\hline
\end{tabular}

\subsection{Adjusted short run marginal cost}

As noted in the previous Section, analysis of whether rich solvent should be stored at any time also requires consideration of a subsequent period of operation where stored solvent can be regenerated, i.e. a full 'solvent storage cycle' needs to be assessed. Chalmers and Gibbins (2007) introduced the concept of an 'adjusted short run marginal cost' (aSRMC) of electricity production to allow insights 
into whether rich solvent storage is an attractive operating mode. The adjustment made to SRMC (short run marginal cost) to calculate aSRMC in the case of rich solvent storage is that costs for solvent regeneration must be included in decision-making to determine the preferred operating mode, even though they are not actually incurred until an operating period some time after the rich solvent has been stored. Only once this adjustment has been made do operators have a valid measure of short run costs that can be used in an analogous way to the conventional SRMC (which does not involve any connection to future costs) for making operating decisions.

Assuming that the costs associated with solvent regeneration are spread equally over the entire period when rich solvent is stored, aSRMC can be defined as:

$\operatorname{aSRMC}_{r s s}=S R M C_{r s s}+$ CCScost $_{r s s}+\left[\left(\right.\right.$ regencost $^{*}$ time $\left._{\text {regen }}\right) /\left(\right.$ MWout $_{r s s} *$ time $\left.\left._{r s s}\right)\right]$

given that:

CCScost $_{r s s}=$ CCSopex $^{*}$ CO2store rss $_{\text {S }}$

and:

$S R M C_{r s s}=$ fuel_price $/ \eta_{r s s}+$ baseopex $+\left[C O 2 \_\right.$price $*(1-\%$ cap $\left.) * f u e l C O 2 / \eta_{r s s}\right]$

Where:

$\%$ cap is the design level of $\mathrm{CO}_{2}$ captured, as a percentage of $\mathrm{CO}_{2}$ produced

$\eta_{r s s}$ is the plant net LHV efficiency while rich solvent is stored (e.g. in \%LHV)

aSRMC $_{r s s}$ is the adjusted SRMC during rich solvent storage (e.g. in $\$ / M W h$ )

baseopex is the operating expenditure for the base power plant (e.g. in $\$ / M W h$ )

CCScost $r_{r s}$ is the direct cost of regenerating and storing $\mathrm{CO}_{2}$ in rich solvent (e.g. in $\$ / M W h$ )

CCSopex is the operating expenditure for $\mathrm{CO}_{2}$ capture, transport and storage (e.g. in $\$ / t C \mathrm{O}_{2}$ )

$\mathrm{CO} 2$ price is the $\mathrm{CO}_{2}$ price (e.g. in $\$ / \mathrm{tCO}_{2}$ )

$\mathrm{CO}_{2}$ store $_{r s s}$ is $\mathrm{CO}_{2}$ stored per unit electrical energy output during rich solvent storage (e.g. in $t \mathrm{CO}_{2} / \mathrm{MWh}$ )

fuelCO2 is the $\mathrm{CO}_{2}$ produced per unit of heat energy from fuel (e.g. in $t \mathrm{CO}_{2} / G J$ )

fuel_price is fuel price, as delivered to the power plant, per unit heat output (\$/GJ)

MWout ${ }_{r s s}$ is the (average) plant output during rich solvent storage (e.g. in MW)

regencost is the change in short run net cash flow during regen. of stored solvent (e.g. in \$/hr), as defined further below

$S R M C_{r s s}$ is the unadjusted short run marginal cost for rich solvent storage (e.g. in $\$ / M W h$ )

time $_{\text {regen }}$ is the total time for additional solvent to be regenerated (e.g. in hr)

time $_{r s s}$ is the total time during which rich solvent is stored (e.g. in hr)

\subsubsection{Costs during additional regeneration}

For an aSRMC for solvent storage to be calculated, it is necessary to determine the relevant cost of additional regeneration (regencost). This should include consideration of the reduced electricity sales revenue due to reduced electrical output associated with the regeneration of stored solvent and also the implications of any requirement to reduce fuel input due to a constraint on solvent regeneration and/or $\mathrm{CO}_{2}$ export capacity. An appropriate definition is, therefore, that: 
regencost $=$ opcflow $w_{\text {noregen }}-$ opcflow $w_{\text {regen }}$

regencost $=\left(\right.$ elecsell $\left._{\text {regen }}-S R M C_{\text {noregen }}\right) * M W o u t_{\text {noregen }}$

$$
-\left(\text { elecsell }_{\text {regen }}-S R M C_{\text {regen }}\right) * M W o u t_{\text {regen }}
$$

given that:

$S R M C_{\text {regen }}=$ fuel_price $/ \eta_{\text {regen }}+$ baseopex $+\left[C O 2 \_\right.$price $*(1-\%$ ocap $\left.) * f u e l C O 2 / \eta_{\text {regen }}\right]$

$$
+\left[\text { CCSopex*\%cap } * \text { fuelCO2/ } \eta_{\text {regen }}\right]
$$

Where:

elecsell $_{\text {regen }}$ is the wholesale electricity price when solvent may be regenerated (e.g. in $\$ / M W h$ )

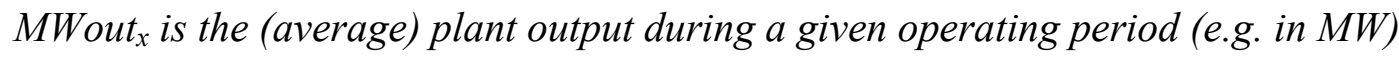

noregen is the counterfactual mode if stored solvent is not being regenerated

opcllow $_{x}$ is the plant net cash flow per unit time during a given operating period (e.g. in $\left.\$ / h r\right)$

regen is the additional regeneration operating mode

regencost is the change in short run net cash flow during regen. of stored solvent (e.g. in $\$ / h r$ )

$S R M C_{x}$ is the short run marginal cost of electricity generation (e.g. in $\$ / M W h$ )

For regencost to be calculated it is necessary to define an operating strategy for regeneration of stored rich solvent and also for the counterfactual case where stored rich solvent is not being regenerated (i.e. if rich solvent had not previously been stored and so required regeneration, how would a power plant have been operated during the period when this stored solvent is being regenerated?). Worked examples to illustrate the principles of this analytical approach are included in Appendix A.

The quantitative analysis in this paper focuses on the test cases outlined in Table 2 (Section 4.2) where stored rich solvent is assumed to be regenerated in addition to rich solvent loaded with $\mathrm{CO}_{2}$ from ongoing operations, with heat for this combined solvent regeneration being supplied using steam from the power plant steam cycle. For the counterfactual operating choice, two cases are considered in the analysis presented in this paper: the power plant not being operated at all or being operated at full load with design capture rate respectively. It is assumed that $\mathrm{CO}_{2}$ price over the period of a solvent storage cycle is constant and that stored rich solvent would only be regenerated during periods when wholesale electricity price is lower than during the period when the rich solvent was stored. A direct result of these assumptions is that a regencost counterfactual case where the capture plant would be operating with the capture plant bypassed is not relevant here (since the driver for this, the ratio between electricity and carbon prices, is lower than during the period when rich solvent was stored, in preference to capture plant bypassing).

Figure 3 plots the cost of additional solvent regeneration (regencost in 1000\$/hr of rich solvent storage) for three wholesale electricity prices that could be observed during periods of additional solvent regeneration for a range of test cases when coal costs $\$ 2.2 / G J$. Short run marginal cost (SRMC) with full $\mathrm{CO}_{2}$ capture operating (and no rich solvent storage) varies from \$34.5/MWh to $\$ 44 / \mathrm{MWh}$ for the range of $\mathrm{CO}_{2}$ prices considered here $\left(\$ 0-100 / \mathrm{CO}_{2}\right)$. This is reflected in the different counterfactual choices noted for each electricity price. 

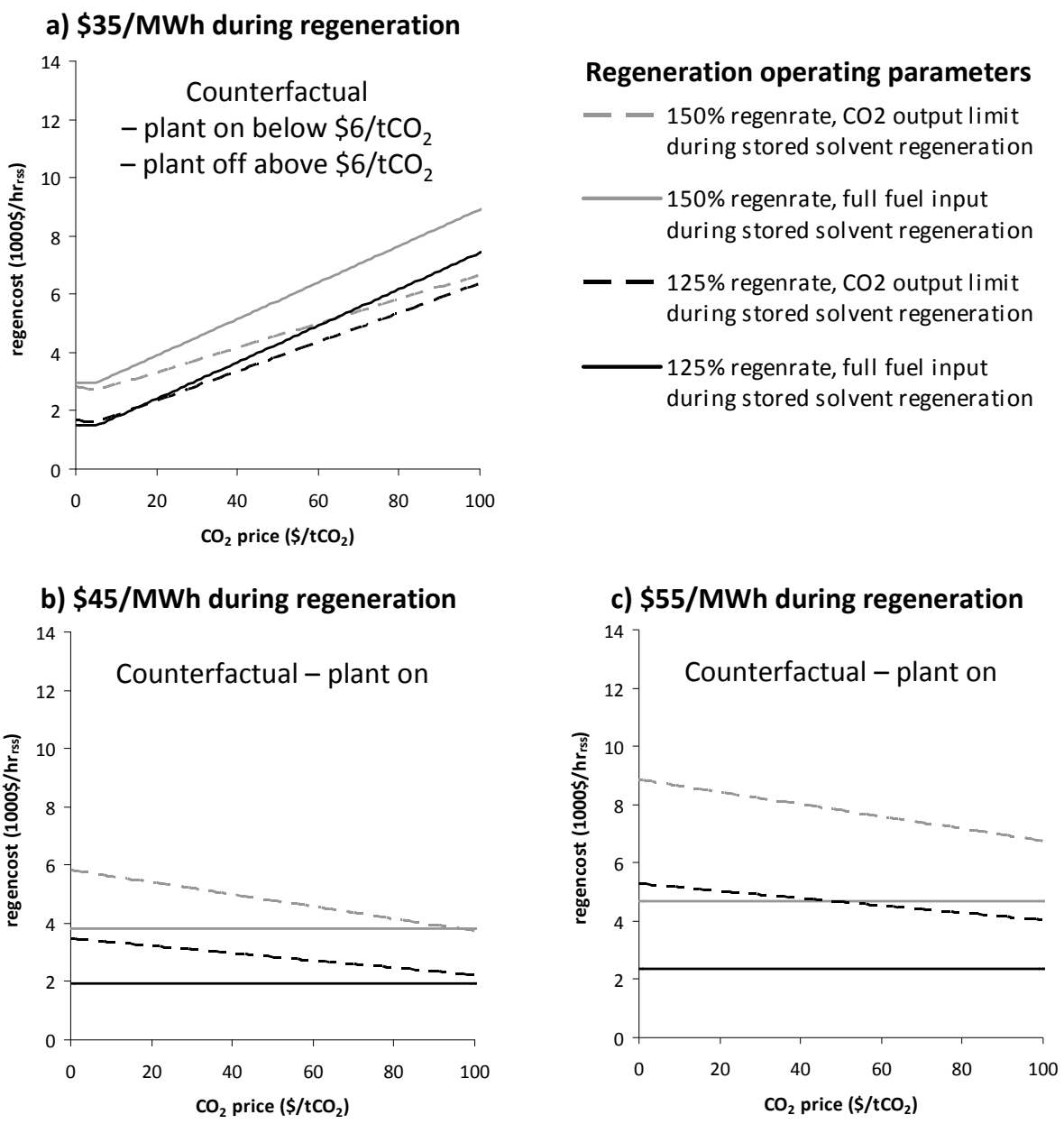

Figure 3 The cost of additional solvent regeneration (regencost) for a range of test case values for varying $\mathrm{CO}_{2}$ price during regeneration

In this first order screening analysis, it has been assumed that the proportion of $\mathrm{CO}_{2}$ produced by combustion that is captured (\%cap) remains constant at all times when CCS is used (i.e. during periods when solvent storage is being used and periods when solvent is being regenerated continuously). For cases where the counterfactual operating choice if stored solvent did not need to be regenerated is operation with full fuel input and $\mathrm{CO}_{2}$ capture, there is no change in the amount of $\mathrm{CO}_{2}$ emitted by choosing to use an operating pattern including solvent storage. The cost of additional solvent regeneration is, therefore, independent of $\mathrm{CO}_{2}$ price and the only significant costs during the period when stored rich solvent is regenerated are related to lost electrical output.

By contrast, a reduction in fuel input during periods of solvent regeneration can lead to regeneration costs being dependent on $\mathrm{CO}_{2}$ price when they are calculated as cost per unit time. Operation at part load tends to reduce power plant efficiency. Set against this, however, reduced fuel input reduces all of the major contributions to total operating costs since there is an associated decrease in fuel costs and also in the amount of $\mathrm{CO}_{2}$ produced and, hence, emitted or captured and stored. It is, therefore, important to note that the total time, and hence total cost, to regenerate stored solvent should also be considered in determining optimum operating strategies. For example, if a decrease in $\$ / \mathrm{hr}$ regeneration cost is accompanied by an increase in the time taken to regenerate stored solvent then it is necessary to assess whether the decrease in hourly cost is sufficiently large to outweigh the longer operating period for which that cost is incurred.

\subsubsection{Illustrative values for adjusted SRMC}


Figure 4 plots adjusted SRMC (aSRMC) during the period when rich solvent is stored for the four test case approaches for regenerating stored solvent considered in this work. As above, illustrative worked examples are included in Appendix A. Considering aSRMC values (rather than SRMC alone) makes a useful contribution to decision-making in this case, since aSRMC includes the solvent regeneration costs that an operator is committed to if they store rich solvent rather than regenerating it continuously. Since the need to regenerate solvent eventually is unavoidable, these costs should be fully integrated when the decision is taken on whether or not to operate with solvent being stored instead of being continuously regenerated.

a) $\$ 35 / M W h$ during regeneration

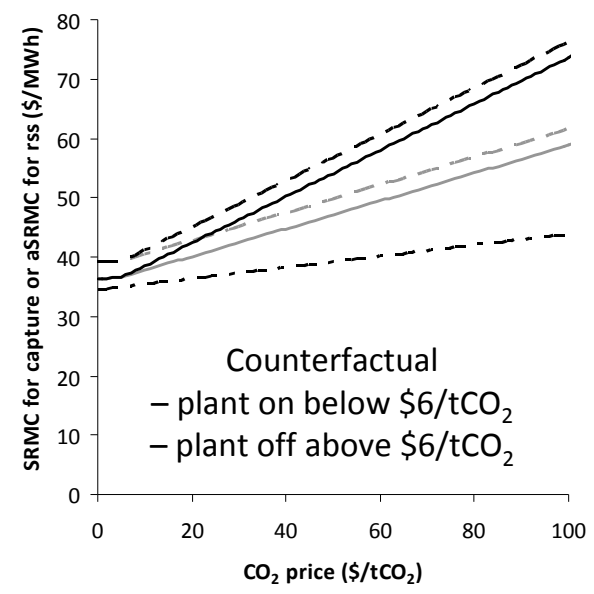

b) $\$ 45 / \mathrm{MWh}$ during regeneration

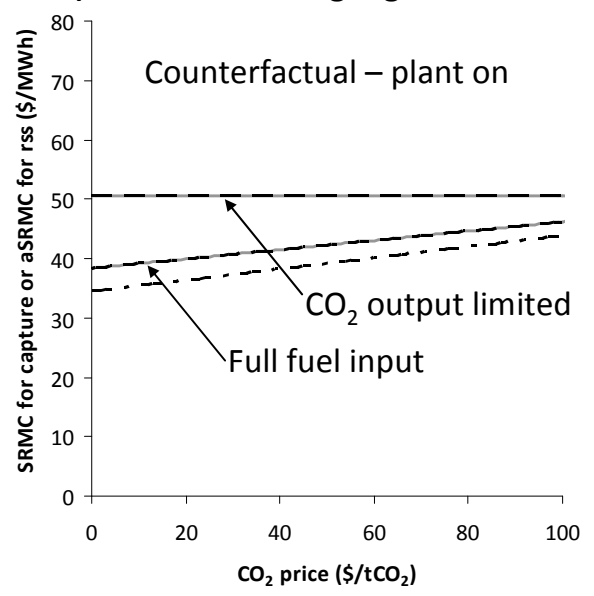

\section{Regeneration operating parameters}

$-150 \%$ regenrate, $\mathrm{CO} 2$ output limit during stored solvent regeneration

$150 \%$ regenrate, full fuel input during stored solvent regeneration

- $125 \%$ regenrate, $\mathrm{CO} 2$ output limit during stored solvent regeneration

- $125 \%$ regenrate, full fuel input during stored solvent regeneration

- - - CO2 capture with no solvent storage or stored solvent regeneration

\section{c) $\$ 55 / \mathrm{MWh}$ during regeneration}

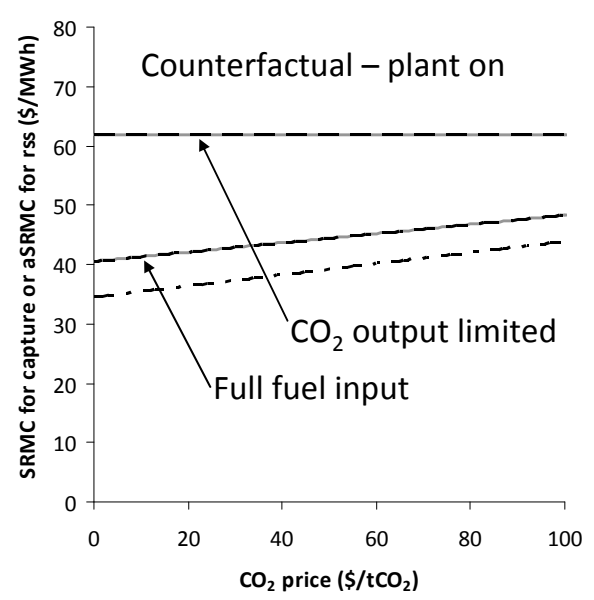

Figure 4 Adjusted short run marginal cost for rich solvent storage for selected test cases

When aSRMC values are considered, variations in total time taken for later regeneration of stored rich solvent are taken into account. By comparing aSRMC with SRMC for power plant operation without solvent storage, an initial indication of whether solvent storage might be economically attractive can, therefore, be obtained. Lower values of SRMC or aSRMC can generally be expected to indicate a more attractive operating option.

It is important to note, however, that plants using solvent storage are able to sell more electrical energy into the electricity network during the period when rich solvent is stored due to their higher net efficiency during that period (although total electrical energy production over a complete solvent storage cycle is slightly reduced). Figure 4 indicates a general result that SRMC for operation with rich solvent storage is higher than SRMC for operation with $\mathrm{CO}_{2}$ capture and no use of solvent storage. This is expected since operation with solvent storage and delayed regeneration is assumed to slightly reduce overall efficiency of electrical energy production. Section 5.2 will 
show, however, that when aSRMC with solvent storage and SRMC without solvent storage have similar values, operation with solvent storage may lead to improved economic performance due to increased revenue during periods (typically with relatively high wholesale electricity prices) when storing solvent increases electrical energy dispatched to consumers, compared to a plant that does not store solvent.

One important result illustrated here is that aSRMC during the period when rich solvent is being stored is independent of regeneration rate later if there is no change in $\mathrm{CO}_{2}$ capture rate or fuel input due to changes in timing for regenerating solvent as part of a solvent storage cycle. It, therefore, seems likely that plant operators would seek to maximise the volumes of solvent stored and, hence, regeneration rate when stored rich solvent is regenerated. The maximum possible regeneration rate when full fuel input is maintained during periods when stored rich solvent is regenerated will, however, depend on investment decisions that determine the installed capacity of the solvent regeneration and compression system and also any limits on the amount of $\mathrm{CO}_{2}$ that can be exported to transport and storage systems.

For the range of $\mathrm{CO}_{2}$ prices considered here, if fuel input is reduced to allow stored solvent to be regenerated, aSRMC is higher than for cases where fuel input is maintained at the design $100 \%$ load ('maximum') value. It is also independent of both regeneration rate and $\mathrm{CO}_{2}$ price. Several factors contribute to this result, including that the total time for the solvent storage cycle varies but the change in total fuel input for a complete cycle of solvent storage is independent of the stored solvent regeneration rate for the cases considered here and modelling assumptions used. For example, as already noted, it is assumed that the proportion of $\mathrm{CO}_{2}$ produced by combustion that is captured (\%cap) is constant for all cases where the plant operates with $\mathrm{CO}_{2}$ capture.

When the wholesale electricity price is $\$ 35 / \mathrm{MWh}$ regenerating stored rich solvent requires that the power plant is switched on during a period when it would not otherwise be generating electricity for the majority of $\mathrm{CO}_{2}$ prices shown on Figure 4(a). In contrast to the other cases discussed above, aSRMC then depends strongly on the rate at which stored solvent is regenerated. A key consideration here is the time period for which the power plant is assumed to need to operate at a short run loss to allow rich solvent to be regenerated. As would be expected intuitively, minimising the time that the plant is required to operate for a given fuel input leads to better economic performance. Although it is beyond the scope of this paper, this result also suggests that further work to explore whether economically attractive alternatives to providing heat for solvent regeneration can be identified in these cases would be useful.

It should also be noted that the assumed use of maximum fuel input for the results shown in Figure 4(a) may represent a non-optimal approach to regenerating stored solvent in the case above with an electricity price of $\$ 35 / \mathrm{MWh}$. When there is no benefit in exporting electricity it may instead be preferable to reduce fuel input to increase the solvent regeneration and $\mathrm{CO}_{2}$ compression capacity available for regenerating stored solvent so that the total time to regenerate stored solvent is reduced, as illustrated in Figure 5. The additional case considered here illustrates a scenario where fuel input is reduced to the same level (i.e $80 \%$ of the $100 \%$ design input) as the $125 \%$ regeneration case, but with a limit on $\mathrm{CO}_{2}$ output that is the same as the amount of $\mathrm{CO}_{2}$ produced when $125 \%$ regeneration rate is combined with full fuel input (i.e. the regeneration rate is increased to 156\%). During periods when the plant only operates if stored solvent must be regenerated, this additional case can give better economic performance for some $\mathrm{CO}_{2}$ and electricity price combinations than the case where full fuel input is maintained. 


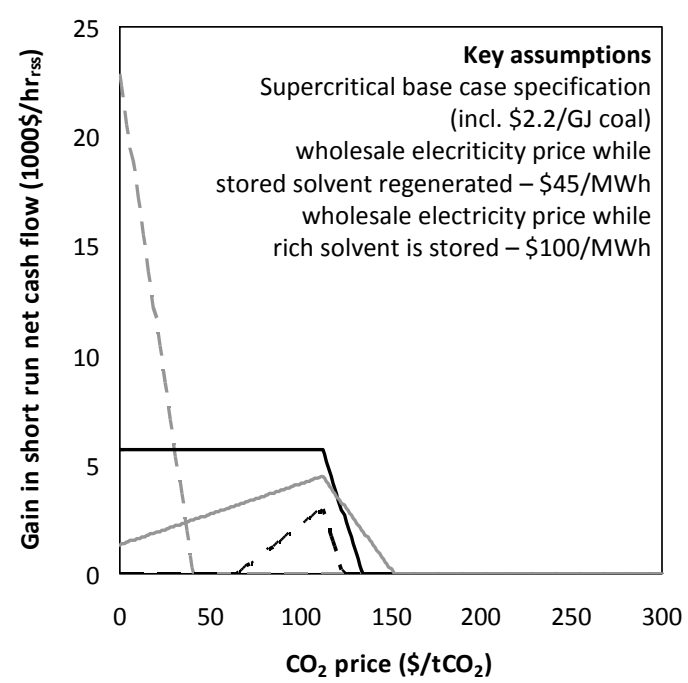

- bypass

— rich solvent storage - full fuel input and $125 \%$ regenrate during solvent regeneration

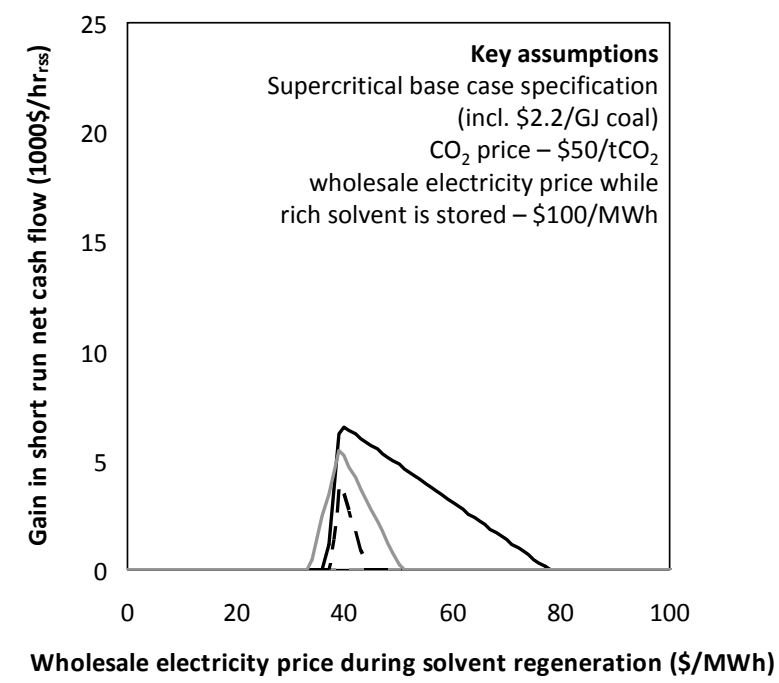

rich solvent storage - $80 \%$ fuel input and $156 \%$ regenrate during solvent regeneration

- - rich solvent storage - CO2 output limit and $125 \%$ regenrate ( $80 \%$ fuel input) during solvent regeneration

Figure 5 Gain in short run net cash flow with rich solvent storage for an alternative approach to regenerating stored solvent

Finally, it is important to note that a significant difference between SRMC and aSRMC is that aSRMC depends on the assumed wholesale electricity price during regeneration of stored solvent, whereas SRMC is independent of wholesale electricity prices. It is then necessary to understand variations in aSRMC during the period when rich solvent is stored as the assumed wholesale electricity price during periods of regeneration of stored rich solvent changes. Figure 6, therefore, plots changes in aSRMC during the period when rich solvent is stored as a function of wholesale electricity price during the period when stored solvent is regenerated. The constant value of SRMC for operation with $\mathrm{CO}_{2}$ capture and continuous regeneration of solvent is also shown for comparison. Similar patterns of results are observed throughout the $\mathrm{CO}_{2}$ price range of $\$ 0$ $100 / \mathrm{tCO}_{2}$ considered in the quantitative analysis in this paper, so Figure 6 considers only a $\$ 50 / \mathrm{tCO}_{2}$ test case.

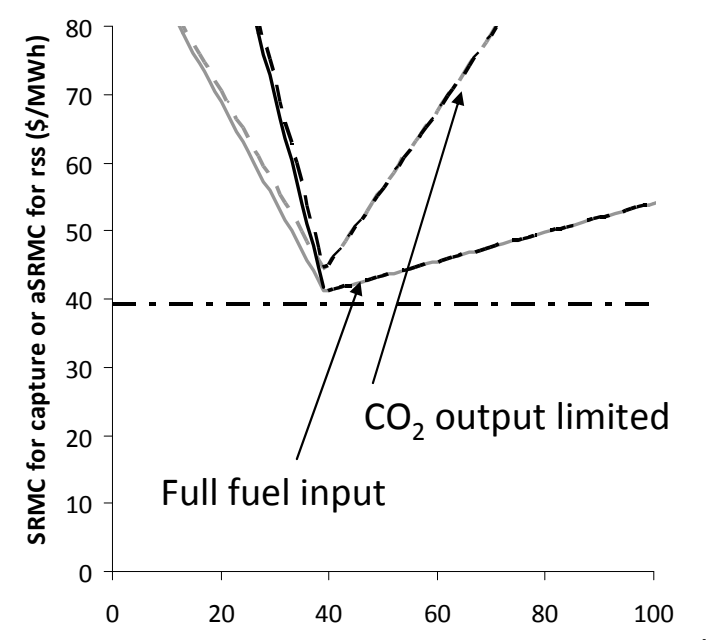

Wholesale electricity price during stored solvent regeneration $(\$ / \mathrm{MWh})$

\section{Regeneration operating parameters}

- $-150 \%$ regenrate, CO2 output limit during stored solvent regeneration

$150 \%$ regenrate, full fuel input during stored solvent regeneration

- $-125 \%$ regenrate, CO2 output limit during stored solvent regeneration

$-125 \%$ regenrate, full fuel input during stored solvent regeneration

- - - CO2 capture with no solvent storage or stored solvent regeneration

Figure 6 Adjusted short run marginal cost for rich solvent storage for $\$ 50 / \mathrm{tCO}_{2}$ as a function of the wholesale electricity price during regeneration of stored storage 
The minimum aSRMC occurs when the wholesale electricity price during additional regeneration is equal to the SRMC of the plant operating with 'normal' $\mathrm{CO}_{2}$ capture. In regions where wholesale electricity price during additional regeneration is below this value, SRMC for rich solvent storage increases as the electricity price falls. These are cases where the power plant would not operate unless stored rich solvent must be regenerated; a lower electricity price, therefore, implies an increase in losses. For cases where wholesale electricity price during additional regeneration is above this value, the power plant would be operating even if additional solvent regeneration was not required. Higher wholesale electricity prices then lead to a higher aSRMC since there is a larger opportunity cost associated with the lost output during the period of additional solvent regeneration.

\subsection{Short run net cash flow}

SRMC (short run marginal cost) with or without adjustment, as appropriate, is a useful indicator for operators. It is, however, insufficient to provide all the information needed in cases where the amount of electrical energy output from a power plant that is available to be sold to the network varies between different available operating modes. In the case studies considered in this paper, it is assumed that additional capacity is made available to the electricity network when rich solvent is stored (or the capture plant is bypassed). It is, therefore, necessary to use a metric that includes consideration of changes in electricity sales revenue as a result of changes in electrical energy dispatched.

The alternative metric proposed in this paper is 'short run net cash flow', which is an example of the widely used economic concept of 'cash flow' defined as the difference between revenue and costs. 'Short run' indicates that only costs or revenues that can be avoided by an operating decision are included in the analysis. This means that electricity sales revenues and short run costs that are only occurred if the plant is operated (e.g. fuel purchase, $\mathrm{CO}_{2}$ emissions allowances etc) are considered, but fixed costs, which cannot be changed by operating decisions (e.g. initial capital required), are not considered. Since fixed costs cannot be changed by operating decisions, it is also reasonable to conclude that they do not affect operating decisions.

\subsubsection{Decision diagrams for operating decisions}

Break-even points where short run net cash flows are equal can be calculated (e.g. as in Appendix A) and plotted on decision diagrams, as in Figure 7. The decision diagrams shown in this paper use the familiar axes of $\mathrm{CO}_{2}$ price and wholesale electricity price (that apply over a period where an operating decision is being made - so the period when rich solvent may be stored for the case studies in this paper). For the illustrative example in Figure 7, it is assumed that the wholesale electricity price during additional solvent regeneration is $\$ 45 / \mathrm{MWh}$ (a somewhat arbitrary choice of the middle of the illustrative values considered above) and that sufficient investment has been made to allow the solvent regeneration rate to be either $125 \%$ or $150 \%$, since aSRMC does not depend on solvent regeneration rate for the cases considered here (see Figure 4 and related discussion). All other input data is outlined in Tables 1-3. 


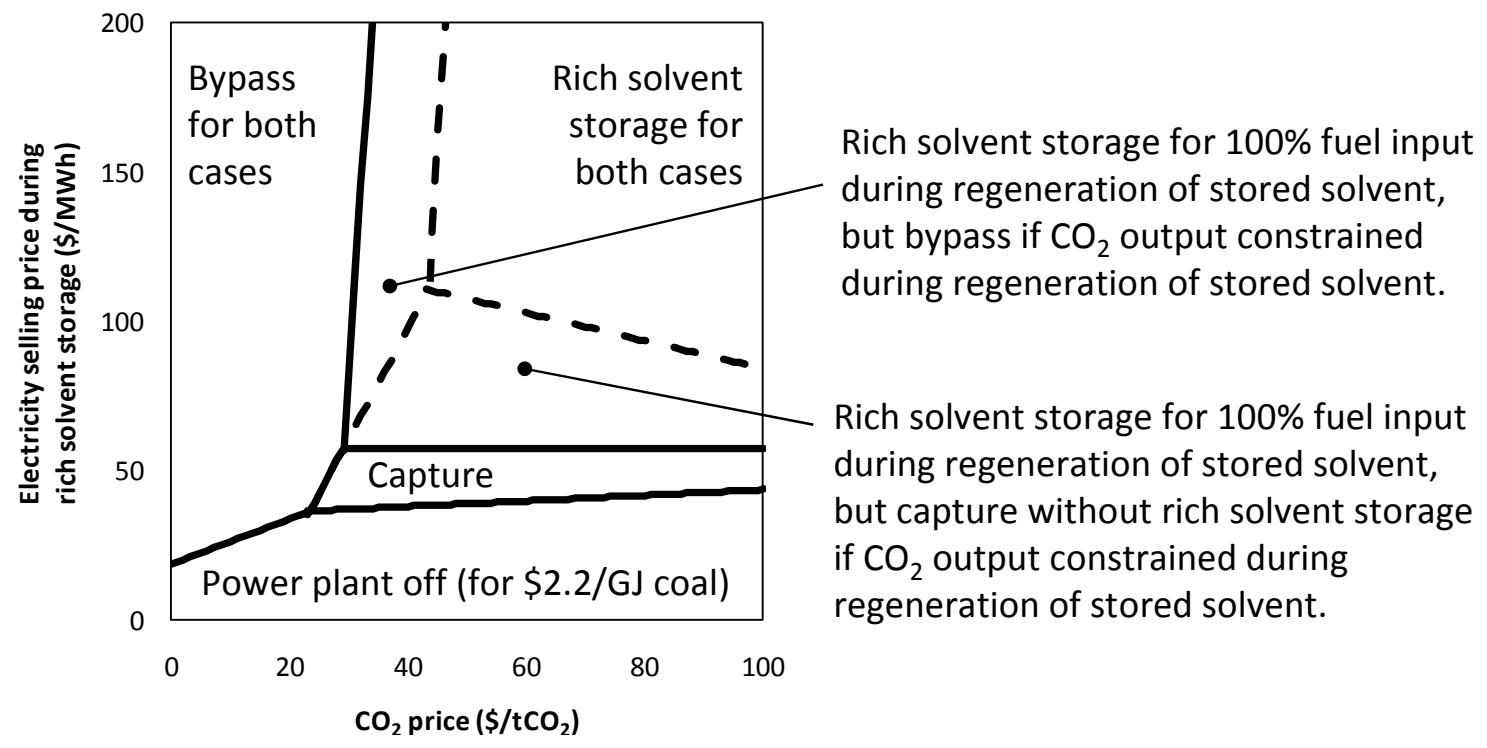

\section{Figure 7 Illustrative decision diagram with capture plant bypass and rich solvent storage available}

When a solvent storage cycle (i.e. rich solvent storage combined with the period when stored solvent is regenerated and lean solvent is stored) does not lead to a change in fuel input or a change in total $\mathrm{CO}_{2}$ captured, the breakeven electricity selling price between operating with $\mathrm{CO}_{2}$ capture with and without solvent storage is independent of $\mathrm{CO}_{2}$ price. If the fuel input is decreased during additional regeneration (i.e. to limit the amount of $\mathrm{CO}_{2}$ that has to be handled) then the crossover wholesale electricity price for switching between continuous solvent regeneration and rich solvent storage decreases slightly with increasing $\mathrm{CO}_{2}$ price. The significant factor here is the reduced residual $\mathrm{CO}_{2}$ emissions during the period when additional solvent is regenerated; less fuel is then burned with a constant capture rate assumed.

One important feature of rich solvent storage being available (when combined with periods where the costs of regenerating stored solvent are relatively modest) is that the region where capture plant bypass would be economically attractive is significantly reduced. It can also be seen that the $\mathrm{CO}_{2}$ price for an operator to cross over from using a capture plant bypass to using capture with rich solvent storage (and vice versa) varies less with changes in wholesale electricity price than for the cross over from operating with capture plant bypass to operating with 'conventional' $\mathrm{CO}_{2}$ capture with continuous solvent regeneration. One consideration here is that the change in power plant output is obviously much smaller in the former cross over case than in the latter.

\subsubsection{Variations in short run net cash flow}

Although decision diagrams, such as Figure 7, are useful tools it is important that these are combined with a good understanding of the key sensitivities that can affect the location of cross over points between different operating options. It is also useful to check the significance of changes in the magnitude of short run net cash flow (and, hence, profitability) when different operating options are available to operators.

For example, Figure 8 illustrates typical patterns in the absolute value of short run net cash flow with and without rich solvent storage, and associated changes in short run net cash flow associated with having rich solvent storage available. An important feature here is that there is a change at around $\$ 110-115 / \mathrm{tCO}_{2}$ in the choice of counterfactual for the period when stored solvent is regenerated, with the counterfactual cases being, respectively, operation only at lower $\mathrm{CO}_{2}$ prices and the power plant switched off at higher $\mathrm{CO}_{2}$ prices. The short run net cash flow for a plant operating with rich solvent storage directly reflects this change in counterfactual operating choice 
since the costs associated with storing rich solvent include those related to changing the way that the power plant would operate during the period when stored rich solvent is being regenerated.

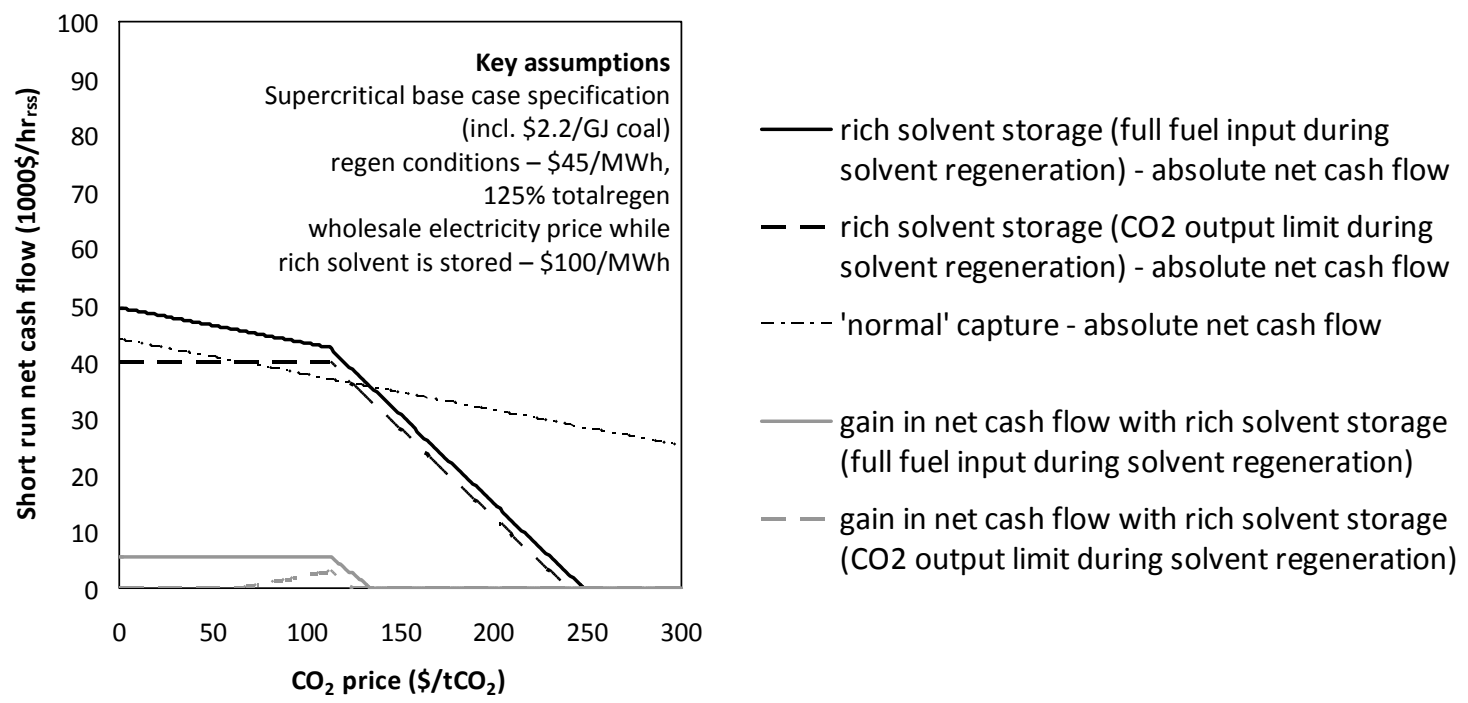

Figure 8 Net short run cash flow gain operating with rich solvent storage for two test cases

In the case where full fuel input is maintained during the period when stored solvent is regenerated, the gain in short run net cash flow is independent of $\mathrm{CO}_{2}$ price when the counterfactual operating choice (if stored solvent was not being regenerated) would be to operate with capture, so at prices below about $\$ 112 / \mathrm{tCO}_{2}$ for this illustrative example. This is because total fuel burned and, hence, residual $\mathrm{CO}_{2}$ emissions are not affected by the decision to store rich solvent, given that it is assumed that $90 \%$ of produced $\mathrm{CO}_{2}$ is captured whenever $\mathrm{CO}_{2}$ capture is used. There is a sharp decrease in short run net cash flow for cases where the counterfactual operating choice during additional regeneration is for the power plant to be off, with rich solvent storage unattractive for $\mathrm{CO}_{2}$ prices above around $\$ 135 / \mathrm{tCO}_{2}$.

Where $\mathrm{CO}_{2}$ output (into a $\mathrm{CO}_{2}$ transport system) during additional regeneration is limited to the same level as occurs during 'normal' operation with full fuel input and full capture, a rather different pattern is observed. In this case, the absolute value of short run net cash flow is independent of $\mathrm{CO}_{2}$ price when the counterfactual choice for the period when stored solvent is regenerated would be to operate with $\mathrm{CO}_{2}$ capture. This is expected since aSRMC is also independent of $\mathrm{CO}_{2}$ price for this case, as shown above. There is then a relatively small region of $\mathrm{CO}_{2}$ prices where storing rich solvent improves short run net cash flow, since fuel input (and, hence, electrical energy output) is limited during regeneration of stored solvent.

Additionally, a distinct maximum in the additional short run net cash flow associated with rich solvent storage is observed in this case. This occurs for the $\mathrm{CO}_{2}$ price at which SRMC for operating with $\mathrm{CO}_{2}$ capture at full fuel input is equal to the wholesale electricity price during regeneration of stored solvent. At this point, the loss associated with reducing fuel input is minimised since there is no lost revenue from reduced electrical energy output when compared to higher wholesale electricity prices. At the same time, there is also no additional cost for producing electrical energy at lower wholesale electricity prices that would not be produced unless a power plant has to be switched on in order to allow stored solvent to be regenerated.

A general conclusion from this discussion, that would be expected intuitively, is that projected wholesale electricity prices during periods when stored solvent is regenerated could play a critical role in determining whether or not rich solvent storage is economically attractive. Figure 9, therefore, plots the gain in short run net cash flow for a broader range of wholesale electricity prices during the period when stored rich solvent is regenerated. The gain in short run net cash flow 
associated with capture plant bypass is also shown. It is clear that the potential for increases in short run net cash flow associated with capture plant bypass is very different to the potential gains associated with rich solvent storage. Although capture plant bypass can have a much higher gain in short run net cash flow associated with it, the scope to use it is generally limited to relatively low $\mathrm{CO}_{2}$ prices. By contrast, although the maximum possible gain in short run net cash flow is lower, rich solvent storage could be an attractive option for a much broader range of $\mathrm{CO}_{2}$ prices.
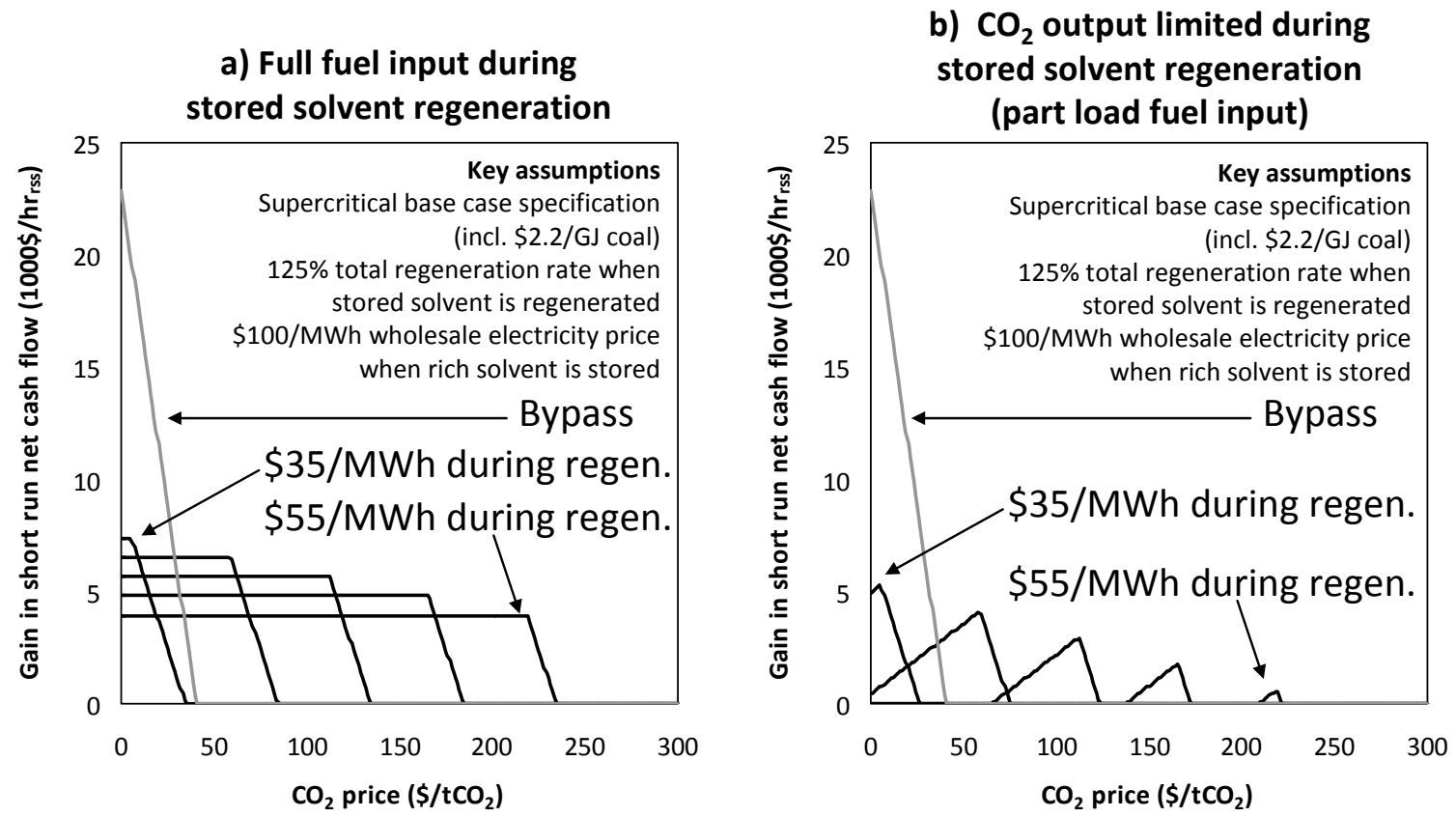

Figure 9 Net short run cash flow gain operating with rich solvent storage for multiple cases

It should also be noted that, in the high $\mathrm{CO}_{2}$ price regions in Figure 9 where rich solvent storage is not economically attractive, an important factor is the assumption that the power plant would be switched off if it were not regenerating stored solvent. In reality, it is possible that factors other than wholesale electricity price (e.g. provision of ancillary services) might lead to a power plant remaining on, even though wholesale electricity prices alone are not sufficient to cover the SRMC of electrical energy production. In these cases, the cost of regenerating stored solvent would change since the impact of storing rich solvent on the choice of operating mode during the period when stored rich solvent is regenerated would have been removed or reduced (depending on the nonregenerating electricity output level). It appears likely that this would often lead to reduced costs associated with storing rich solvent.

\section{Discussion and scope for further work}

Section 5 presented results from a first order techno-economic screening analysis that can be used to determine whether rich solvent storage could be an important operating mode in determining the economic performance of a supercritical coal-fired power plant retrofitted with post-combustion capture. Investors and decision-makers using first order analyses such as this can then compare the range of wholesale electricity prices that would be required for rich solvent storage to be economically attractive (in combination with other revenue streams that are not quantified in this paper, where appropriate) with plausible ranges of future wholesale electricity price in the jurisdiction where a power plant with $\mathrm{CO}_{2}$ capture might be built. This should allow them to determine whether or not it is worthwhile to consider solvent storage in more detail. 
The quantitative analysis presented here considered alternative strategies for regenerating stored solvent. Where regenerating stored rich solvent does not require a reduction in fuel input, solvent storage could often be the most economically attractive option on a short run basis for scenarios where $\mathrm{CO}_{2}$ prices are at least $\$ 40-50 / \mathrm{tCO}_{2}$. If a reduction in fuel input is required to allow stored rich solvent to be regenerated this could limit the attractiveness of solvent storage to situations where the counterfactual operating choice when stored rich solvent is being regenerated is that the power plant is operating anyway, possibly at reduced output. Generally, solvent storage is most likely to be economically attractive when wholesale electricity prices are similar to SRMC for 'normal' operation with $\mathrm{CO}_{2}$ capture (i.e. without rich solvent storage) during the periods when stored solvent is regenerated.

In reality, there will be a trade-off between operating expenditure during regeneration of stored solvent and capital expenditure that will determine the size of the relevant components of the capture plant and also of the base power plant (and of the $\mathrm{CO}_{2}$ transport and storage system). This paper does not attempt to determine the optimal approach for investors. Instead it proposes an analytical method based on understanding potential changes in short run net cash flow that could be used within feasibility studies by investors (and others) or by asset owners making operating decisions for a plant that has already been built. This method should allow improved understanding of whether or not changes in operating options available to power plant operators through rich solvent storage (and/or capture plant bypass or other modes of flexible operation) could be sufficiently significant to warrant further investigation in more detailed design studies or in operational decision-making for existing plants.

Although it is beyond the scope of this paper, it should be possible to extend the techniques developed in this paper to include additional costs and revenue streams, such as costs related to start-up, shutdown and revenues for the provision of ancillary services. The inclusion of start-up and shutdown costs would require careful consideration of the period considered for calculating short-run revenues. A complete treatment of ancillary services would be likely to need full integration of options for part-load operation into the techno-economic model used in this paper, since part-load operation would be expected to enhance some of the services that could be offered by the plant operator.

It is also important to note that a range of additional operating approaches could improve the economic performance of solvent storage. In some cases, power plants may operate at part load even if stored rich solvent is not being regenerated. This would increase the range of (often favourable) scenarios where no change in fuel input is needed for stored rich solvent to be regenerated in plants without additional $\mathrm{CO}_{2}$ handling capacity. Additionally, in cases where a plant that would otherwise be inoperative is operated in order to allow stored rich solvent to be regenerated, then reduced fuel input levels, and consequently fuel supply costs, could be beneficial since they would allow increased regeneration rates within 'normal' $\mathrm{CO}_{2}$ handling limits and also give decreased absolute operating costs.

Another area where there is scope for further work is in exploring cases where alternative heat sources are available for regenerating stored solvent. Gibbins and Crane (2004) showed that integration between the power plant steam cycle and post-combustion capture unit tends to improve overall thermal efficiencies. It is, therefore, appropriate to undertake initial screening analysis of operating decisions for the integrated plant configuration used in this paper. There may, however, be sites where alternative low cost external sources of heat are available that could be attractive for regenerating stored solvent.

Although the focus of this paper has been a post-combustion capture case study it is also expected that the analytical methods applied in this paper could be extended to other $\mathrm{CO}_{2}$ capture 
technologies. For example, liquid oxygen (LOX) storage could be used at oxyfuel and IGCC power plants and there is also potential for interim hydrogen storage when pre-combustion $\mathrm{CO}_{2}$ capture is used. The case of LOX storage could be particularly interesting. The main energy requirement when LOX is stored is electrical energy to run an air separation unit (ASU). This could readily be provided from the electricity network at the current price of electricity during the 'regeneration' period when the LOX store is being replenished, thus removing the need to run the base power plant if it is uneconomical to do so.

Finally, another potentially significant development in recent years has been increased interest, in some jurisdictions, in the use of $\mathrm{CO}_{2}$ capture at power plants firing natural gas. Natural gas-fired power plants have typically provided flexible electricity supply in many electricity networks and usually have relatively high fuel prices (and lower capital costs) than coal plants. This suggests that a thorough exploration of the potential value of flexible operation is important if natural gas plants are fitted with $\mathrm{CO}_{2}$ capture.

\section{Conclusions}

The IPCC (2005) special report on CCS indicated that $\mathrm{CO}_{2}$ capture retrofits at existing power plants could be important in order to avoid premature closure of these plants. At the time of writing, a number of commercial-scale demonstration projects that would retrofit $\mathrm{CO}_{2}$ capture at existing plant sites are under consideration (e.g. SaskPower, 2011; ScottishPower, 2010). An important development in this area since IPCC (2005) has been improved understanding of the significance of avoiding, or at least delaying, new power plant construction.

There has, however, been very limited work undertaken to establish whether the 'built-in' flexibility that could be available at many power plants retrofitted with post-combustion is important. This paper has, therefore, developed a methodology for techno-economic screening analysis to improve understanding of some options for flexible operation of power plants, and has applied it to the case study of a well-integrated retrofit of post-combustion capture at a supercritical coal-fired power plant. First order models of power plant efficiency under different operating modes underpin this study and refine the work reported in Chalmers and Gibbins (2007).

The study reported in this paper confirms the observation made by Haines and Davison (2009) that "the revenue increase which could be obtained in any one day [by using solvent storage] varies considerably depending greatly on the shape of the daily price curve." Their work was, however, limited to an initial exploration of whether solvent storage may be economically attractive for operation in response to historical wholesale electricity prices in one market. By considering a range of test cases and developing a flexible modelling approach where multiple input variables can be determined by the modeller, an improved understanding of key factors that lead to this conclusion is obtained by the work presented in this paper. For example, it is clear that solvent storage is much more likely to be economically attractive in jurisdictions where electricity prices are in the region of the SRMC for operation with 'normal' $\mathrm{CO}_{2}$ capture during periods when stored rich solvent is regenerated.

A significant characteristic of the methods developed in this paper is that they consider changes in short run net cash flow at power plants (i.e. not only SRMC). An important feature of many retrofitted plants could be 'built-in' flexibility to increase their output when $\mathrm{CO}_{2}$ capture is bypassed or rich solvent is stored. The value of the operating modes that this feature enables can, however, only be determined if these changes in electrical energy delivered to the electricity network are included in the analysis; conventional SRMC analysis is insufficient. 
The illustrative case study considered here suggests that rich solvent storage could be an attractive operating mode in some electricity networks. It is necessary, however, for investors and other decision-makers to consider if and how solvent storage might be used on a site-by-site basis (e.g. depending on expectations of fuel, $\mathrm{CO}_{2}$ and electricity price). There is also scope for a broader range of operating options to be considered. For example, low cost heat sources might avoid the need to operate a power plant so that stored rich solvent can regenerated when it would otherwise not be operating. Additionally, if it is necessary to keep a power plant running only to regenerate stored rich solvent, it is possible that reducing fuel input will be beneficial. Under certain conditions this allows stored solvent to be regenerated more quickly with an associated reduction in additional fuel costs.

\section{Acknowledgements}

The work reported in this paper was financially supported by the UK Energy Research Centre (www.ukerc.ac.uk). Discussion and debate with several colleagues, particularly Mathieu Lucquiaud, and comments from two anonymous peer reviewers are also gratefully acknowledged. All views and interpretations expressed are, however, entirely the responsibility of the authors.

\section{Appendix A Worked examples}

\section{A1. Regencost (Figure 3)}

$$
\begin{array}{r}
\text { regencost }=\left(\begin{array}{l}
\text { elecsell } \\
\text { regen }
\end{array}-S R M C_{\text {noregen }}\right) * M W o u t_{\text {noregen }} \\
-\left(\text { elecsell }_{\text {regen }}-S R M C_{\text {regen }}\right) * M W o u t_{\text {regen }}
\end{array}
$$

To calculate regencost it is first necessary to check whether the power plant would be operating during the period when solvent is expected to be regenerated. This is done by comparing the expected wholesale electricity price with the SRMC for available operating modes. For this first order analysis, it is assumed that the decision is made by comparing wholesale electricity selling price to SRMC. The plant will operate if wholesale electricity selling price is above SRMC. If it is economically attractive to store rich solvent at an electricity selling price that is higher than the price assumed for later regeneration it is already known that capture plant bypass is not an economically attractive option during the period of additional regeneration. It is, therefore, assumed that the only operating choices available to operators as an alternative to regenerating stored solvent are that the plant is off or operating with full (90\%) capture.

Table 4 shows illustrative examples where $\mathrm{CO}_{2}$ price is $\$ 50 / \mathrm{tCO}_{2}$ and it is assumed the operator chooses $125 \%$ regenrate while stored solvent is regenerated. Cases with and without a constraint on $\mathrm{CO}_{2}$ output (see Table 2) are reported. All other input assumptions are as stated in Tables 1 and 3.

Table 4 Illustrative values of regencost

\begin{tabular}{|l|c|c|}
\hline $\begin{array}{l}\text { Expected wholesale electricity price during regeneration of stored } \\
\text { solvent (elecsel| }\end{array}$ regen) & \$35/MWh & \$45/MWh \\
\hline $\begin{array}{l}\text { SRMC for operating with 90\% } \mathrm{CO}_{2} \text { capture (and no regeneration of } \\
\text { stored solvent) during this period }\end{array}$ & \$39.4/MWh & \$39.4/MWh \\
\hline Counterfactual operating decision & Off & $\begin{array}{c}\text { On with full } \\
\text { capture }\end{array}$ \\
\hline $\begin{array}{l}\text { Capacity dispatched with counterfactual operating decision assuming } \\
\text { full fuel input (MWout }\end{array}$ & 0MWegen
\end{tabular}




\begin{tabular}{|l|c|c|}
\hline Regencost for 125\% regenrate and no constraint on $\mathrm{CO}_{2}$ export & $\$ 4.4 \times 10^{3} / \mathrm{hr}$ & $\$ 1.9 \times 10^{3} / \mathrm{hr}$ \\
\hline $\begin{array}{l}\text { SRMC for operating with 125\% regenrate with } \mathrm{CO}_{2} \text { export constrained } \\
\text { to be no more than 'normal' operation with } 90 \% \mathrm{CO}_{2} \text { capture }\end{array}$ & $\$ 43.1 / \mathrm{MWh}$ & $\$ 43.1 / \mathrm{MWh}$ \\
\hline $\begin{array}{l}\text { Capacity dispatched with 125\% regenerate with } \mathrm{CO}_{2} \text { export constrained } \\
\text { to be no more than 'normal' operation with } 90 \% \mathrm{CO}_{2} \text { capture }\end{array}$ & $489 \mathrm{MW}$ & $489 \mathrm{MW}$ \\
\hline $\begin{array}{l}\text { Regencost for } 125 \% \text { regenrate with } \mathrm{CO}_{2} \text { export constrained to be no } \\
\text { more than 'normal' operation with } 90 \% \mathrm{CO}_{2} \text { capture }\end{array}$ & $\$ 3.95 \times 10^{3} / \mathrm{hr}$ & $\$ 2.8 \times 10^{3} / \mathrm{hr}$ \\
\hline
\end{tabular}

\section{A2. Adjusted short run marginal cost (Figure 4)}

$\operatorname{aSRMC}_{r s s}=S R M C_{r s s}+$ CCScost $_{r s s}+\left[\left(\right.\right.$ regencost $^{*}$ time $\left._{\text {regen }}\right) /\left(\right.$ MWout $_{r s s} *$ time $\left.\left._{r s s}\right)\right]$

Once regencost has been calculated it is used as an input value to determine adjusted SRMC for the period when rich solvent is being stored. In other words, SRMC during the period when rich solvent stored is adjusted to take into account the commitment to pay costs for regenerating stored solvent later. Table 5 reports the values for all of the variables needed to calculate aSRMC $\mathrm{rss}_{\text {, }}$ except regencost. It is assumed that rich solvent it stored for 1 hour (time rss $=1 \mathrm{hr}$ ), that $\mathrm{CO}_{2}$ price is $\$ 50 / \mathrm{tCO}_{2}$ and that the regenrate is $125 \%$, Other basic data is from Tables $1-3$.

Table 5 Illustrative values for calculating adjusted SRMC while rich solvent is stored

\begin{tabular}{|c|c|}
\hline Parameter & Value \\
\hline Unadjusted SRMC while rich solvent is stored (SRMC $\left.{ }_{\mathrm{rss}}\right)$ & \$23.3/MWh \\
\hline $\begin{array}{l}\text { Direct cost of regenerating and permanently storing } \mathrm{CO}_{2} \text { temporarily stored in rich } \\
\text { solvent }\left(\mathrm{CCS} \operatorname{cost}_{\mathrm{rss}} \text { ) }\right.\end{array}$ & \$9.6/MWh \\
\hline $\begin{array}{l}\text { Total time for stored solvent to be regenerated later with no constraint on } \mathrm{CO}_{2} \\
\text { export (time } e_{\text {regen }} \text { ) }\end{array}$ & $4 \mathrm{hr}$ \\
\hline $\begin{array}{l}\text { Total time for stored solvent to be regenerated later with } \mathrm{CO}_{2} \text { export constrained to } \\
\text { be no more than 'normal' operation with } 90 \% \mathrm{CO}_{2} \text { capture (time }{ }_{\text {regen }} \text { ) }\end{array}$ & $5 \mathrm{hr}$ \\
\hline $\begin{array}{l}\text { Capacity dispatched while rich solvent is stored, assuming full fuel input } \\
\text { (MWout }{ }_{\text {rss }} \text { ) }\end{array}$ & 803MW \\
\hline
\end{tabular}

To calculate aSRMC $\mathrm{Crs}_{\mathrm{r}}$ it is then necessary for an operator to assume a wholesale electricity price for the later period when stored solvent will be regenerated. This allows regencost to be calculated. Table 6 provides illustrative values for $\mathrm{aSRMC}_{\mathrm{rss}}$ for the regencost examples calculated in Table 4 .

Table 6 Illustrative aSRMC rss $_{\text {for }} 4$ examples

\begin{tabular}{|l|c|c|}
\hline & $\begin{array}{c}\$ 35 / \mathrm{MWh} \text { electricity price } \\
\text { assumed during later regeneration } \\
\text { of stored solvent }\end{array}$ & $\begin{array}{c}\text { \$45/MWh electricity price } \\
\text { assumed during later } \\
\text { regeneration of stored solvent }\end{array}$ \\
\hline $\begin{array}{l}\text { No constraint on } \mathrm{CO}_{2} \text { export (i.e. full fuel input } \\
\text { assumed during regeneration) }\end{array}$ & $\$ 54.8 / \mathrm{MWh}$ & $\$ 42.4 / \mathrm{MWh}$ \\
\hline $\begin{array}{l}\mathrm{CO}_{2} \text { export constrained to be no more than } \\
\text { 'normal' operation with } 90 \% \mathrm{CO}_{2} \text { capture }\end{array}$ & $\$ 57.4 / \mathrm{MWh}$ & $\$ 50.5 / \mathrm{MWh}$ \\
\hline
\end{tabular}

\section{A3. Short run net cash flow and breakeven electricity selling prices (Figure 7)}

aSRMC is a useful indicator to compare to conventional SRMC for operating options that do not include a commitment to costs that will be incurred later. Comparison of costs per unit of electricity delivered could, however, sometimes lead to non-optimal decisions. This is because the different operating modes being considered in this analysis allow different amounts of electrical energy to be delivered to the electricity network (given assumed maximum fuel input).

It is, therefore, necessary to consider short run net cash flow to ensure that optimal operating decisions are made. In particular, it is possible to determine 'breakeven' points where two operating modes would be equally attractive to the operator. These can be plotted on a 'decision diagram' such as Figure 7, so that operators (and other practitioners) have a visual guide to determine preferred operating mode. 
For plants operating without solvent storage, short run net cash flow is defined as:

$S R N C F_{x}=\left(\right.$ elecsell $\left._{x}-S R M C_{x}\right) * M W_{\text {out }}$

For a plant operating with solvent storage, during the period when solvent is stored, the equivalent expression is:

$S R N C F_{r s s}=\left(\right.$ elecsell $\left._{x}-a S R M C_{r s s}\right) * M W o u t_{r s s}$

The decision diagram in Figure 7 is for a case where is assumed that the wholesale electricity price during regeneration of stored solvent will be $\$ 45 / \mathrm{MWh}$. Table 7 shows SRMC, aSRMC and capacity dispatched to the electricity system (MWout) for different operating modes that may be available to the plant operator when it is assumed that $\mathrm{CO}_{2}$ price is $\$ 50 / \mathrm{tCO}_{2}$ and other input data is as outlined in Tables 1-3.

Table 7 Illustrative SRMC, aSRMC and MWout for Figure 7 with $\$ 50 / \mathrm{tCO}_{2}$

\begin{tabular}{|l|c|c|}
\hline Operating mode & SRMC or aSRMC (\$/MWh) & Capacity delivered (MW) \\
\hline Off & 0 & 0 \\
\hline On - capture plant bypass & 57.4 & 823 \\
\hline On - full capture, no solvent storage & 39.4 & 670 \\
\hline On - solvent storage, no $\mathrm{CO}_{2}$ export constraint & 42.4 & 803 \\
\hline On - solvent storage, $\mathrm{CO}_{2}$ export constraint & 50.5 & 803 \\
\hline
\end{tabular}

In this case, it is never economically favourable to operate with capture plant bypass if the $\mathrm{CO}_{2}$ price is $\$ 50 / \mathrm{tCO}_{2}$ or higher for the range of wholesale electricity prices considered on the decision diagram in Figure 7. It is also important to note, however, that there is a relatively small difference between SRMC for operating with full capture and aSRMC operating with solvent storage, particularly if there is no $\mathrm{CO}_{2}$ handling constraint. It can, therefore, be expected that as wholesale electricity price increases the additional capacity available when solvent is stored will lead to this operating mode becoming more attractive. This is illustrated in Table 8, where short run net cash flow for a range of wholesale electricity prices is shown. All input data assumptions are the same as in Table 7 , including an assumed $\mathrm{CO}_{2}$ price of $\$ 50 / \mathrm{tCO}_{2}$. The cases where two operating decisions are possible are where SRNCF is the same for those two operating modes.

Table 8 Short run net cash flow for illustrative wholesale electricity prices in Figure 7

\begin{tabular}{|c|c|c|c|c|}
\hline $\begin{array}{l}\text { Wholesale } \\
\text { electricity price } \\
\text { (\$/MWh) }\end{array}$ & Operating decision & $\begin{array}{c}\text { SRNCF with } \\
\text { capture, no solvent } \\
\text { storage }(1000 \$ / h r)\end{array}$ & $\begin{array}{c}\text { SRNCF with solvent } \\
\text { storage, no } \mathrm{CO}_{2} \\
\text { export constraint } \\
(1000 \$ / \mathrm{hr})\end{array}$ & $\begin{array}{c}\text { SRNCF with solvent } \\
\text { storage, with } \mathrm{CO}_{2} \\
\text { export constraint } \\
(1000 \$ / \mathrm{hr})\end{array}$ \\
\hline 30.0 & Off & -6.2 & -10.0 & -16.5 \\
\hline 39.4 & $\begin{array}{l}\text { Off or operate with capture } \\
\text { (no solvent storage) }\end{array}$ & 0 & -2.4 & -8.9 \\
\hline 45.0 & $\begin{array}{l}\text { Operate with capture (no } \\
\text { solvent storage) }\end{array}$ & 3.8 & 2.1 & -4.4 \\
\hline 57.5 & $\begin{array}{l}\text { Operate with capture (no } \\
\text { solvent storage) or with } \\
\text { solvent storage if no } \mathrm{CO}_{2} \\
\text { export constraint }\end{array}$ & 12.1 & 12.1 & 5.6 \\
\hline 75.0 & $\begin{array}{l}\text { Operate with solvent } \\
\text { storage if no } \mathrm{CO}_{2} \text { export } \\
\text { constraint, otherwise } \\
\text { operate with capture (no } \\
\text { solvent storage) }\end{array}$ & 23.9 & 26.2 & 19.7 \\
\hline 107.1 & $\begin{array}{l}\text { Operate with capture (no } \\
\text { solvent storage) or with }\end{array}$ & 45.2 & 51.7 & 45.2 \\
\hline
\end{tabular}




\begin{tabular}{|l|l|c|c|c|}
\hline & $\begin{array}{l}\text { solvent storage, with } \mathrm{CO}_{2} \\
\text { export constraint }\end{array}$ & & \\
\hline 150.0 & $\begin{array}{l}\text { Operate with solvent } \\
\text { storage, even if there is a } \\
\mathrm{CO}_{2} \text { export constraint }\end{array}$ & 74.1 & 86.4 & 79.9 \\
\hline
\end{tabular}

\section{References}

(All web references last accessed on $2^{\text {nd }}$ August 2011)

Chalmers H and Gibbins J (2007) Initial Evaluation of the Impact of Post-combustion Capture of Carbon Dioxide on Supercritical Pulverised Coal Power Plant Part Load Performance. Fuel 86(14), 2109-2123.

Chalmers H, Lucquiaud M, Gibbins J and Leach M (2009) Flexible Operation of Coal Fired Power Plants with Post Combustion Capture of Carbon Dioxide. American Society of Civil Engineers: Journal of Environmental Engineering 135(6), 449-458.

Chalmers H (2010a) Operating options for coal-fired power plants with $\mathrm{CO}_{2}$ capture. London, UK. Report CCC/160. London, UK. IEA Clean Coal Centre.

Chalmers H (2010b) Flexible operation of coal-fired power plants with post-combustion capture of carbon dioxide. Thesis submitted to the University of Surrey for the degree of Doctor of Philosophy.

Chalmers H, Leach M and Gibbins J (2011) Built-in flexibility at retrofitted power plants: what is it worth and can we afford to ignore it? Energy Procedia 4, 2596-2603.

Cohen, S., Chalmers, H., Webber, M.E. and King, C.W. (2011) Comparing post-combustion $\mathrm{CO}_{2}$ capture operation at retrofitted coal-fired power plants in the Texas and Great Britain electric grids. Environmental Research Letters 6 (2), 024001, doi:10.1088/1748-9326/6/2/024001

Cohen SM, Rochelle GT and Webber ME (2008) Turning $\mathrm{CO}_{2}$ capture on \& off in response to electric grid demand: a baseline analysis of emissions and economics. Proceedings of ASME Energy Sustainability 2008 (ES2008), Jacksonville, Florida, USA, 10-14 August.

Cohen SM, Fyffe J, Rochelle GT and Webber ME (2009a) The effect of fossil fuel prices on flexible $\mathrm{CO}_{2}$ capture operation. Proceedings of ASME Energy Sustainability 2009 (ES2009), Jacksonville, Florida, 19-23 July.

Cohen S (2009b) Grid and Process Modeling of Flexible Post-Combustion $\mathrm{CO}_{2}$ Capture. Presented at IEA Greenhouse Gas R\&D Programme workshop on Operating Flexibility of Power Plants with CCS, London, UK, 11-12 November. http://www.ieaghg.org/docs/

flexibility\%20workshop/05_Flexibility\%20workshop\%20Cohen.pdf

Davison J and Thambimuthu K (2009) An overview of technologies and costs of carbon dioxide capture in power generation. Proceedings of the Institution of Mechanical Engineers: Part A, Journal of Power and Energy 223, 201-212.

Doosan Babcock (2009) Doosan Babcock announces world-leading carbon capture project with US utility Basin Electric Power Cooperative. Press release, 21 Dec 2009. www.doosanbabcock.com. 
DTI (1999) Technology Status Report 009: Supercritical Steam Cycles for Power Generation Applications. UK Government Department of Trade and Industry Cleaner Coal Technology Programme.

Fuss S, Szolgayova J, Obersteiner M and Gusti M (2008) Investment under market and climate policy uncertainty. Applied Energy 85, 708-721.

Gibbins JR and Crane RI (2004) Scope for reductions in the cost of $\mathrm{CO}_{2}$ capture using flue gas scrubbing with amine solvents. Proceedings of the Institution of Mechanical Engineers, Part A: Journal of Power and Energy 218, 231-239.

Haines MR and Davison JE (2009) Designing carbon capture power plants to assist in meeting peak power demand. Energy Procedia 1(1), 1457-1464.

Holt N, Booras G and Schoff R (2009) EPRI IGCC Engineering \& Economic Evaluations -2009. Presented at 4th International Conference on IGCC \& XtL Technologies, Dresden, Germany, 18-20 May.

IEA GHG (2004) Improvement in power generation with post-combustion capture of $\mathrm{CO}_{2}$. Report PH4/33. Cheltenham, UK. IEA Greenhouse Gas R\&D Programme.

IEA GHG (2006) $\mathrm{CO}_{2}$ capture as a factor in power station investment decisions. Report 2006/8. Cheltenham, UK. IEA Greenhouse Gas R\&D Programme.

IEA GHG (2008) Scoping study on operating flexibility of power plants with $\mathrm{CO}_{2}$ capture. Report 2008/TR1. Cheltenham, UK. IEA Greenhouse Gas R\&D Programme.

IEA GHG (2009) Workshop on Operating Flexibility of Power plants with CCS. http://www.ieaghg.org/index.php?/20100113168/workshop-on-operating-flexibility-of-powerplants-with-ccs.html

IEA GHG (2011) Retrofitting $\mathrm{CO}_{2}$ Capture to Existing Power Plants. Report 2011/2. Cheltenham, UK IEA Greenhouse Gas R\&D Programme.

IPCC (2005) IPCC Special Report on Carbon Dioxide Capture and Storage. Prepared by Working Group III of the Intergovernmental Panel on Climate Change [Metz B, Davidson O, de Coninck HC et al (eds.)]. Cambridge University Press, Cambridge, UK and New York, NY, USA.

Kvamsdal HM, Jakobsen JP and Hoff KA (2009) Dynamic modeling and simulation of a $\mathrm{CO}_{2}$ absorber column for post-combustion $\mathrm{CO}_{2}$ capture. Chemical Engineering and Processing 48(1), 135-144.

Luby P (2003) Supercritical systems. Modern Power Systems, August 2003, 27-32.

Lucquiaud M, Chalmers H and Gibbins J (2007) Potential for flexible operation of pulverised coal power plants with $\mathrm{CO}_{2}$ capture. Energy Materials 2(3), 175-180.

Lucquiaud M, Chalmers H and Gibbins J (2009) Steam turbines for operating and future-proof upgrading flexibility. IEA Greenhouse Gas R\&D Programme workshop on Operating Flexibility of Power Plants with CCS, London, UK, 11-12 November. http://www.ieaghg.org/docs/ flexibility\%20workshop/15_Flexibility\%20workshop\%20Lucquiaud.pdf 
Lucquiaud M (2010) Steam cycle options for capture-ready power plants, retrofits and flexible operation with post-combustion $\mathrm{CO}_{2}$ capture. Thesis submitted to the University of London for the degree of Doctor of Philosophy and for the Diploma of Imperial College.

MIT (2007) The Future of Coal: Options for a Carbon-Constrained World. An MIT interdisciplinary study. Massachusetts Institute of Technology, Boston, MA, USA. http://web.mit.edu/coal/

MIT Energy Initiative (2009) Retrofitting of Coal-Fired Power Plants for $\mathrm{CO}_{2}$ Emissions Reductions: An MIT Energy Initiative Symposium. Massachusetts Institute of Technology. http://web.mit.edu/mitei/research/reports.html

Morgan MG and Henrion M (1990) Uncertainty: A Guide to Dealing with Uncertainty in Quantitative Risk and Policy Analysis. Cambridge University Press, USA.

Ploumen P (2006) Retrofit of $\mathrm{CO}_{2}$ capture at coal-fired power plants in the Netherlands. Proceedings of the $8^{\text {th }}$ International Conference on Greenhouse Gas Control Technologies (GHGT8), Trondheim, Norway, 19-23 June.

Ramezan M, Skone TJ, ya Naskala N and Liljedahl G (2007) Carbon Dioxide Capture from Existing Coal-Fired Power Plants. DOE/NETL-401/110907, Final Report Revised, US Department of Energy National Energy Technology Laboratory. http://www.netl.doe.gov/energyanalyses/pubs/CO2\%20Retrofit\%20From\%20Existing \%20Plants\%20Revised\%20November\%202007.pdf

Sakai K, Morita S and Sato, T (1999) State-of-the-art Technologies for the 1,000-MW 24.5$\mathrm{MPa} / 600^{\circ} \mathrm{C} / 600^{\circ} \mathrm{C}$ Coal-fired Boiler. Hitachi Review 48(5), 273-6.

SaskPower (2011) Boundary Dam Integrated Carbon Capture \& Storage Demonstration Project. http://www.saskpower.com/sustainable_growth/projects/carbon_capture_storage.shtml

ScottishPower (2010) ScottishPower Consortium Through To Final Stages Of UK Government CCS Competition. http://www.scottishpower.com/PressReleases_2017.htm

Szolgayova J, Fuss S and Obersteiner M (2008) Assessing the effects of $\mathrm{CO}_{2}$ price caps on electricity investments-A real options analysis. Energy Policy 36, 3974-3981.

Tenaska Trailblazer Partners, LLC (2011) Steam Turbine Generator Configuration and Sizing Considering the Impacts of Carbon Capture System Availability. Report to the Global CCS Institute. http://cdn.globalccsinstitute.com/sites/default/files/publication_20110331_trailblazersteam-turbine-sizing.pdf

UKCCSC (2011) CCS in the next decade - establishing a UK industry: workshop presentations. Workshop held on $20^{\text {th }}$ June 2011, London, UK. UK CCS Community network. http://www.ukccsc.co.uk/Meetings/industry-readiness-June-2011

Xu B, Stobbs RA, White V, Wall RA et al (2007) Future $\mathrm{CO}_{2}$ capture technology options for the Canadian market. Report No. COAL R309, BERR/Pub URN 07/1251. UK Department of Business Enterprise and Regulatory Reform. http://www.berr.gov.uk/files/file42874.pdf. 